\title{
Proteomic indicators of oxidation and hydration state in colorectal cancer
}

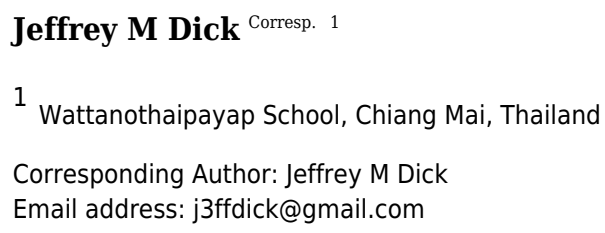

New integrative approaches are needed to harness the potential of rapidly growing datasets of protein expression and microbial community composition in colorectal cancer. Chemical and thermodynamic models offer theoretical tools to describe populations of biomacromolecules and their relative potential for formation in different microenvironmental conditions. The average oxidation state of carbon $\left(Z_{c}\right)$ can be calculated as an elemental ratio from the chemical formulas of proteins, and water demand per residue $\left(n \mathrm{H}_{2} \mathrm{O}\right)$ is computed by writing the overall formation reactions of proteins from basis species. Using results reported in proteomic studies of clinical samples, many datasets exhibit higher mean $\mathrm{Z}_{\mathrm{C}}$ or $\mathrm{nH}_{2} \mathrm{O}$ of proteins in carcinoma or adenoma compared to normal tissue. In contrast, average protein compositions in bacterial genomes often have lower $Z_{c}$ for bacteria enriched in fecal samples from cancer patients compared to healthy donors. In thermodynamic calculations, the potential for formation of the cancer-related proteins is energetically favored by changes in the chemical activity of $\mathrm{H}_{2} \mathrm{O}$ and fugacity of $\mathrm{O}_{2}$ that reflect the compositional differences. The compositional analysis suggests that a systematic change in chemical composition is an essential feature of cancer proteomes, and the thermodynamic descriptions show that the observed proteomic transformations in host tissue could be promoted by relatively high microenvironmental oxidation and hydration states. 


\section{Proteomic indicators of oxidation and hydration state in colorectal cancer}

Jeffrey M. Dick*1

${ }^{1}$ Wattanothaipayap School, Chiang Mai, Thailand 


\section{ABSTRACT}

New integrative approaches are needed to harness the potential of rapidly growing datasets of protein expression and microbial community composition in colorectal cancer. Chemical and thermodynamic models offer theoretical tools to describe populations of biomacromolecules and their relative potential for formation in different microenvironmental conditions. The average oxidation state of carbon $\left(Z_{C}\right)$ can be calculated as an elemental ratio from the chemical formulas of proteins, and water demand per residue $\left(\bar{n}_{\mathrm{H}_{2} \mathrm{O}}\right)$ is computed by writing the overall formation reactions of proteins from basis species. Using results reported in proteomic studies of clinical samples, many datasets exhibit higher mean $Z_{\mathrm{C}}$ or $\bar{n}_{\mathrm{H}_{2} \mathrm{O}}$ of proteins in carcinoma or adenoma compared to normal tissue. In contrast, average protein compositions in bacterial genomes often have lower $Z_{C}$ for bacteria enriched in fecal samples from cancer patients compared to healthy donors. In thermodynamic calculations, the potential for formation of the cancer-related proteins is energetically favored by changes in the chemical activity of $\mathrm{H}_{2} \mathrm{O}$ and fugacity of $\mathrm{O}_{2}$ that reflect the compositional differences. The compositional analysis suggests that a systematic change in chemical composition is an essential feature of cancer proteomes, and the thermodynamic descriptions show that the observed proteomic transformations in host tissue could be promoted by relatively high microenvironmental oxidation and hydration states.

\section{INTRODUCTION}

Datasets for differentially expressed proteins in cancer are often interpreted from a mechanistic perspective that emphasizes molecular interactions. Alternative approaches exemplified by recent models that use information theory demonstrate the possibility of interpreting proteomic expression data in a high-level conceptual framework (Rietman et al., 2016). These approaches may combine concepts from dynamical systems theory and thermodynamics, such as the possible association of "attractor states" in landscape models with low-energy states of a system (Enver et al., 2009; Davies et al., 2011). Despite these advances, energetic functions for differential protein expression have rarely been formulated in terms of physicochemical variables that reflect the conditions of tumor microenvironments. The coupling of recent proteomic data with thermodynamic models using chemical components provides new perspectives on microenvironmental conditions that are conducive to carcinogenesis or healthy growth.

The purpose of the present study is to explore human proteomic and microbial community data for colorectal cancer within a chemical and thermodynamic framework using variables that represent oxidation and hydration state. This is carried out first by comparing chemical compositions of up- and down-expressed proteins along the normal tissue-adenoma-carcinoma progression. Then, a thermodynamic model is used to quantify the overall energetics of the proteomic transformations in terms of chemical potential variables. This approach reveals not only common patterns of chemical changes among many proteomic datasets, but also the possibility that proteomic transformations may be shaped by energetic constraints associated with the changing tumor microenvironment.

Recent years have seen the appearance of many proteomic datasets for colorectal cancer (CRC), a very common and extensively studied type of human cancer. Genomic 
instability is often considered to be the primary driver of cancer progression (Kinzler and Vogelstein, 1996). However, not only genetic transformations, but also microenvironmental dynamics can influence cancer progression (Schedin and Elias, 2004). Many reactions in the microenvironment, such as those involving hormones or cell-cell signaling interactions, operate on fast timescales, but local hypoxia in tumors and other microenvironmental changes can develop and persist over longer timescales. The long timescales of carcinogenesis may be sufficient for cells to adapt their proteomes to the differential energetic costs of biomolecular synthesis imposed by changing chemical conditions of the microenvironment.

One of the characteristic features of tumors is varying degrees of hypoxia (Höckel and Vaupel, 2001). Hypoxic conditions promote activation of hypoxia-inducible genes by the HIF-1 transcription factor and intensify the mitochondrial generation of reactive oxygen species (ROS) (Murphy, 2009), leading to oxidative stress (Höckel and Vaupel, 2001; Semenza, 2008). It is important to note that there is significant intra-tumor and inter-tumor heterogeneity of oxygenation levels (Höckel and Vaupel, 2001; DeBerardinis and Cheng, 2010). Cancer cells can also exhibit changes in oxidation-reduction (redox) state; for example, redox potential (Eh) monitored in vivo in a fibrosarcoma cell line is altered compared to normal fibroblasts (Hutter et al., 1997).

The hydration states of cancer cells and tissues may also vary considerably from their healthy counterparts. Microwave detection of differences in dielectric constant resulting from greater water content in malignant tissue is being developed for medical imaging of breast cancer (Grzegorczyk et al., 2012). IR and Raman spectroscopic techniques also reveal a greater hydration state of cancerous breast tissue, resulting from interaction of water molecules with hydrophilic cellular structures of cancer cells but negligible association with the triglycerides and other hydrophobic molecules that are more common in normal tissue (Abramczyk et al., 2014).

Increased hydration levels may be associated with a higher abundance of hyaluronan found in the extracellular matrix (ECM) of migrating and metastatic cells (Toole, 2002), while a higher subcellular hydration state may alter cell function by acting as a signal for protein synthesis and cell proliferation (Häussinger, 1996). It has also been hypothesized that the increased hydration of cancer cells underlies a reversion to a more embryonic state (McIntyre, 2006). Based on all of these considerations, compositional and thermodynamic variables related to redox and hydration state have been selected as the primary descriptive variables in this study.

As noted by others, it seems paradoxical that hypoxia, i.e. low oxygen partial pressure, could be a driving force for the generation of oxidative molecules. Possibly, the mitochondrial generation of ROS is a cellular mechanism for oxygen sensing (Guzy and Schumacker, 2006). Whether through hypoxia-induced oxidative stress or other mechanisms, proteins in cancer have been found to have a variety of oxidative post-translational modifications (PTM), including carbonylation and oxidation of cysteine residues (Yeh et al., 2010; Yang et al., 2013). Although proteome-level assessments of oxidative PTM are gaining traction (Yang et al., 2013), existing large-scale proteomic datasets may carry other signals of oxidation state. One possible "syn-translational" indicator of oxidation state, inherent in the amino acid sequences of proteins, is the average oxidation state of carbon, which is introduced below. At the outset, it is not clear whether such a metric of oxidation state would more closely track 
hypoxia (i.e. relatively reducing conditions) that may arise in tumors, or a more oxidizing potential connected with ROS and oxidative PTM.

Density functional theory and other computational methods that yield electron density maps of proteins with known structure can be used to compute the partial charges, or oxidation states, of all the atoms. Spectroscopic methods can also be used to determine oxidation states of atoms in molecules (Gupta et al., 2014). These theoretical and empirical approaches offer the greatest precision in an oxidation state calculation, but it is difficult to apply them to the hundreds of proteins, many with undetermined three-dimensional structures, found to have significantly altered expression in proteomic experiments. Other methods for estimating the oxidation states of atoms in molecules may be needed to assess the overall direction of electron flow in a proteomic transformation.

Some textbooks of organic chemistry present the concept of formal oxidation states, in which the electron pair in a covalent bond is formally assigned to the more electronegative of the two atoms (e.g. Hendrickson et al., 1970, ch. 18). This rule is consistent with the current IUPAC recommendations for calculating oxidation state of atoms in molecules, but generalizes the IUPAC definitions such that the oxidation states of different carbon atoms in organic molecules can be distinguished (e.g. Loock, 2011; Gupta et al., 2014). In the primary structure of a protein, where no metal atoms are present and heteroatoms are bonded only to carbon and/or hydrogen, the average oxidation state of carbon $\left(Z_{\mathrm{C}}\right)$ can be calculated as an elemental ratio, which is easily obtained from the amino acid composition (Dick, 2014). In a protein with the chemical formula $\mathrm{C}_{c} \mathrm{H}_{h} \mathrm{~N}_{n} \mathrm{O}_{o} \mathrm{~S}_{s}$, the average oxidation state of carbon $\left(Z_{\mathrm{C}}\right)$ is

$$
Z_{\mathrm{C}}=\frac{3 n+2 o+2 s-h}{c}
$$

This equation is equivalent to others, also written in terms of numbers of the elements $\mathrm{C}$, $\mathrm{H}, \mathrm{N}, \mathrm{O}$ and $\mathrm{S}$, used for the average oxidation state of carbon in algal biomass (Bohutskyi et al., 2015), in humic and fulvic acids (Fekete et al., 2012), and for the nominal oxidation state of carbon in dissolved organic matter (Riedel et al., 2012).

Comparing the average carbon oxidation states in organic molecules is useful for quantifying the reactions of complex mixtures of organic matter in aerosols (Kroll et al., 2011), the growth of biomass (Hansen et al., 1994) and the production of biofuels (Borak et al., 2013; Bohutskyi et al., 2015). There is a considerable range of the average oxidation state of carbon in different amino acids (Masiello et al., 2008; Amend et al., 2013), with consequences for the energetics of synthesis depending on environmental conditions (Amend and Shock, 1998). Similarly, the nominal oxidation state of carbon can be used as a proxy for the standard Gibbs energies of oxidation reactions of various organic and biochemical molecules (Arndt et al., 2013). The oxidation state concept can be used as a bookkeeping tool to understand electron flow in metabolic pathways, yet may receive limited coverage in biochemistry courses (Halkides, 2000). There has been scant attention in the literature to the differences in carbon oxidation state among proteins or other biomacromolecules. Nevertheless, the ease of computation makes $Z_{\mathrm{C}}$ a useful metric for rapidly ascertaining the direction and magnitude of electron flow associated with proteomic transformations during disease progression. 
Comparisons of oxidation states of carbon can be used to rank the energetics of reactions of organic molecules in particular systems (Amend et al., 2013). However, quantifying the energetics and mass-balance requirements of chemical transformations requires a more complete thermodynamic model. Thermodynamic models that are based on chemical components (or basis species), i.e. a minimum number of independent chemical formula units that can be combined to form any chemical species in the system, have an established position in geochemistry (Anderson, 2005; Bethke, 2008). The implications of choosing different sets of components, called the "basis" (Bethke, 2008), have received relatively little discussion in biochemistry, although Alberty (2004) in a similar context highlighted the observation made by Callen (1985) that " $[t]$ he choice of variables in terms of which a given system is formulated, while seemingly an innocuous step, is often the most crucial step in the solution". Models built with different choices of components nevertheless yield equivalent results when consistently parameterized (Morel and Hering, 1993; Ravi Kanth et al., 2014). Accordingly, components are a type of chemical accounting for reactions in a system (Morel and Hering, 1993), and do not necessarily constitute mechanistic models for those reactions.

The structure and dynamics of the hydration shells of proteins have important biological consequences (Levy and Onuchic, 2006) and can be investigated in molecular simulation studies (Wedberg et al., 2012). Statistical thermodynamics can be used to assess the effects of preferential hydration of protein surfaces on unfolding or other conformational changes (Lazaridis and Karplus, 2003). However, there is also a role for $\mathrm{H}_{2} \mathrm{O}$ as a chemical component in stoichiometric reactions representing the mass-balance requirements for formation of proteins with different amino acid sequences.

For example, a system of proteins composed of $\mathrm{C}, \mathrm{H}, \mathrm{N}, \mathrm{O}$ and $\mathrm{S}$ can be described using the (non-innocuous) components $\mathrm{CO}_{2}, \mathrm{NH}_{3}, \mathrm{H}_{2} \mathrm{~S}, \mathrm{O}_{2}$ and $\mathrm{H}_{2} \mathrm{O}$. Accordingly, stoichiometric reactions representing the formation of certain proteins at the expense of others during a proteomic transformation generally have non-zero coefficients on $\mathrm{O}_{2}$, $\mathrm{H}_{2} \mathrm{O}$ and the other components. These stoichiometric reactions can be written without specific knowledge of electron density in proteins or hydration by molecular $\mathrm{H}_{2} \mathrm{O}$.

It bears repeating that reactions written using chemical components are not mechanistic representations. Instead, these reactions are specific statements of the requirement for mass balance that can be used to build thermodynamic models of chemically reacting systems (Helgeson et al., 2009). Flux-balance models of metabolic networks integrate stoichiometric constraints (e.g. Hiller and Metallo, 2013), but stoichiometric descriptions of proteomic transformations are less common, perhaps because of a greater degree of abstraction away from elementary reactions. Nevertheless, the differentially down- and up-expressed proteins in a proteomic dataset furnish a quantitative description of a proteomic transformation and can be viewed as the initial and final states of a chemically reacting system, which is then amenable to thermodynamic modeling.

The chemical potentials of components can be used to describe the internal state of a system and, for an open system, its relation to the environment. Oxygen fugacity is a variable that is related to the chemical potential of $\mathrm{O}_{2}$; it does not necessarily reflect the concentration of $\mathrm{O}_{2}$, but instead indicates the distribution of species with different oxidation states (Albarède, 2011). Theoretical calculation of the energetics of reactions 
as a function of oxygen fugacity provides a useful reference for the relative stabilities of organic molecules in different environments (Helgeson et al., 2009; Amend et al., 2013). However, in a cellular context a multidimensional approach may be required to quantify possible microenvironmental influences on the potentials for biochemical transformations. Likely variables include not only oxidation state but also water activity. Scenarios for early metabolic and cellular evolution (Pace, 1991; Russell and Hall, 1997; Damer and Deamer, 2015) lend additional support to the choice of water activity as a primary variable of interest.

A thermodynamic model that is formulated in terms of carefully selected basis species affords a convenient description of a system. As described in the Methods, a basis is selected that reduces the empirical correlation between average oxidation state of carbon and the coefficient on $\mathrm{H}_{2} \mathrm{O}$ in formation reactions of proteins from basis species. The first part of the Results shows compositional comparisons for human and microbial proteins (Sections 3.1-3.2) in 35 datasets from 20 different studies. Many of the comparisons reveal higher $Z_{C}$ or higher water demand for the formation of proteins up-expressed in cancer compared to normal tissue. Contrary to the trends observed for human proteins, the average protein compositions of bacteria enriched in cancer tend to have lower $Z_{C}$.

To better understand the biochemical context of these differences, calculations reported in the second part of the Results use chemical affinity (negative Gibbs energy of reaction) to predict the most stable molecules as a function of oxygen fugacity and water activity (Sections 3.3-3.5). Theoretical calculations of the relative stabilities of groups of up- and down-expressed proteins build on the compositional descriptions as a step toward quantifying the microenvironmental conditions that may promote or impede the proteomic alterations associated with the progression of cancer.

\section{METHODS}

\subsection{Data sources}

This section describes the data sources and additional data processing steps applied in this study. An attempt was made to locate all currently available proteomic studies for clinical tissue on CRC including, among others, those listed in the "Tissue" and "Tissue subproteomes" sections of the review paper by de Wit et al. (2013) and in Supporting Table 3 ("Clinical Samples") of the review paper by Martínez-Aguilar et al. (2013). To make the comparisons more robust, only datasets with at least 30 proteins in each of the up- and down-regulated groups were considered; however, all datasets from a given study were included if at least one of the datasets met this criterion. The reference keys for the selected studies shown below and in Table 1 are derived from the names of the authors and year of publication.

In comparisons between groups of up- and down-expressed proteins, the convention in this study is to consider proteins with higher expression in normal tissue or less-advanced cancer stages as a "normal" group (group 1), with number of proteins $n_{1}$, while proteins with higher expression in cancer or more-advanced cancer stages are categorized as a "cancer" group (group 2), with number of proteins $n_{2}$. For example, in the dataset of Uzozie et al. (2014) comparing normal mucosa and adenoma, the proteins up-expressed in adenoma are assigned to group 2, while in the adenoma-carcinoma 
dataset of Knol et al. (2014), the proteins with higher expression in adenoma are assigned to group 1 (see Table 1).

Names or IDs of genes or proteins given in the sources were searched in UniProt (The UniProt Consortium, 2015). The corresponding UniProt IDs are provided in the *. CSV data files in Dataset S1. Amino acid sequences of human proteins were taken from the UniProt reference proteome (files UP 000005640 _9606. fasta.gz containing canonical, manually reviewed sequences, and UP000005640_9606_additional.fasta.gz containing isoforms and unreviewed sequences, dated 2016-04-13, downloaded from ftp://ftp.uniprot.org/pub/databases/uniprot/current_ release/knowledgebase/reference_proteomes/Eukaryota/). Entire sequences were used; i.e., signal peptides and propeptides were not removed when calculating the amino acid compositions. However, amino acid compositions were calculated for particular isoforms, if these were identified in the sources. Files human.aa.csv and human_additional.aa.csv in Dataset S1 contain the amino acid compositions of the proteins calculated from the UniProt reference proteome. In a few cases, amino acid compositions of unreviewed or obsolete sequences in UniProt, not available in the reference proteome, were individually compiled; these are contained in file human2 . aa . csv in Dataset S1.

Reported gene names were converted to UniProt IDs using the UniProt mapping tool (http: / / www uniprot. org/mapping), and IPI accession numbers were converted to UniProt IDs using the DAVID conversion tool (https: / / david.ncifcrf.gov/content.jsp?file=conversion.html). For proteins with no automatically generated matches, manual searches in UniProt of the protein descriptions, where available, were performed. Proteins with missing or duplicated identifiers, or those that could not be matched to a UniProt ID, were omitted from the comparisons here. Therefore, the numbers of proteins actually used in the comparisons (listed in Table 1) may be different from the numbers of proteins reported by the authors and summarized below.

WTK+0 8: Watanabe et al. (2008) used 2-nitrobenzenesulfenyl labeling and MS/MS analysis to identify 128 proteins with differential expression in paired CRC and normal tissue specimens from 12 patients. The list of proteins used in this study was generated by combining the lists of up- and down-regulated proteins from Table 1 and Supplementary Data 1 of Watanabe et al. (2008) with the Swiss-Prot and UniProt accession numbers from their Supplementary Data 2.

AKP +10: Albrethsen et al. (2010) used nano-LC-MS/MS to characterize proteins from the nuclear matrix fraction in samples from 2 patients each with adenoma (ADE), chromosomal instability CRC (CIN+) and microsatellite instability CRC (MIN+). Cluster analysis was used to classify proteins with differential expression between ADE and $\mathrm{CIN}+, \mathrm{MIN}+$, or in both subtypes of carcinoma (CRC). Here, gene names from Supplementary Tables 5-7 of Albrethsen et al. (2010) were converted to UniProt IDs using the UniProt mapping tool.

JKMF 10: Jimenez et al. (2010) compiled a list of candidate serum biomarkers from a meta-analysis of the literature. In the meta-analysis, 99 up- or down-expressed proteins were identified in at least 2 studies. The list of UniProt IDs used in this study was taken from Table 4 of Jimenez et al. (2010). 
XZC+1 0: Xie et al. (2010) used a gel-enhanced LC-MS method to analyze proteins in pooled tissue samples from 13 stage I and 24 stage II CRC patients and pooled normal colonic tissues from the same patients. Here, IPI accession numbers from Supplemental Table 4 of Xie et al. (2010) were converted to UniProt IDs using the DAVID conversion tool.

ZYS+10: Zhang et al. (2010) used acetylation stable isotope labeling and LTQ-FT MS to analyze proteins in pooled microdissected epithelial samples of tumor and normal mucosa from 20 patients, finding 67 and 70 proteins with increased or decreased expression (ratios $\geq 2$ or $\leq 0.5$ ). Here, IPI accession numbers from Supplemental Table 4 of Zhang et al. (2010) were converted to UniProt IDs using the DAVID conversion tool.

BPV+11: Besson et al. (2011) analyzed microdissected cancer and normal tissues from 28 patients (4 adenoma samples and 24 CRC samples at different stages) using iTRAQ labeling and MALDI-TOF/TOF MS to identify 555 proteins with differential expression between adenoma and stage I, II, III, IV CRC. Here, gene names from supplemental Table 9 of Besson et al. (2011) were converted to UniProt IDs using the UniProt mapping tool.

JCF +11: Jankova et al. (2011) analyzed paired samples from 16 patients using iTRAQ-MS to identify 118 proteins with $>1.3$-fold differential expression between CRC tumors and adjacent normal mucosa. The protein list used in this study was taken from Supplementary Table 2 of Jankova et al. (2011).

MRK+11: Mikula et al. (2011) used iTRAQ labeling with LC-MS/MS to identify a total of 1061 proteins with differential expression (fold change $\geq 1.5$ and false discovery rate $\leq 0.01$ ) between pooled samples of 4 normal colon (NC), 12 tubular or tubulo-villous adenoma (AD) and 5 adenocarcinoma (AC) tissues. The list of proteins used in this study was taken from from Table S8 of Mikula et al. (2011).

KKL+12: Kim et al. (2012) used difference in-gel electrophoresis (DIGE) and cleavable isotope-coded affinity tag (cICAT) labeling followed by mass spectrometry to identify 175 proteins with more than 2 -fold abundance ratios between microdissected and pooled tumor tissues from stage-IV CRC patients with good outcomes (survived more than five years; 3 patients) and poor outcomes (died within 25 months; 3 patients). The protein list used in this study was made by filtering the cICAT data from Supplementary Table 5 of Kim et al. (2012) with an abundance ratio cutoff of $>2$ or $<0.5$, giving 147 proteins. IPI accession numbers were converted to UniProt IDs using the DAVID conversion tool.

KYK+12: Kang et al. (2012) used mTRAQ and cICAT analysis of pooled microsatellite stable (MSS-type) CRC tissues and pooled matched normal tissues from 3 patients to identify 1009 and 478 proteins in cancer tissue with increased or decreased expression by higher than 2 -fold, respectively. Here, the list of proteins from Supplementary Table 4 of Kang et al. (2012) was filtered to include proteins with expression ratio $>2$ or $<0.5$ in both mTRAQ and cICAT analyses, leaving 175 up-expressed and 248 down-expressed proteins in CRC. Gene names were converted to UniProt IDs using the UniProt mapping tool.

WOD+12: Wiśniewski et al. (2012) used LC-MS/MS to analyze proteins in microdissected samples of formalin-fixed paraffin-embedded (FFPE) tissue from 8 patients; at $P<0.01,762$ proteins had differential expression between normal mucosa and primary tumors. The list of proteins used in this study was taken from 
Supplementary Table 4 of Wiśniewski et al. (2012).

YLZ+12: Yao et al. (2012) analyzed the conditioned media of paired stage I or IIA $\mathrm{CRC}$ and normal tissues from 9 patients using lectin affinity capture for glycoprotein (secreted protein) enrichment by nano LC-MS/MS to identify 68 up-regulated and 55 down-regulated differentially expressed proteins. IPI accession numbers listed in Supplementary Table 2 of Yao et al. (2012) were converted to UniProt IDs using the DAVID conversion tool.

MCZ+13: Mu et al. (2013) used laser capture microdissection (LCM) to separate stromal cells from 8 colon adenocarcinoma and 8 non-neoplastic tissue samples, which were pooled and analyzed by iTRAQ to identify 70 differentially expressed proteins. Here, gi numbers listed in Table 1 of Mu et al. (2013) were converted to UniProt IDs using the UniProt mapping tool; FASTA sequences of 31 proteins not found in UniProt were downloaded from NCBI and amino acid compositions were added to human2.aa.csv.

KWA +14: Knol et al. (2014) used differential biochemical extraction to isolate the chromatin-binding fraction in frozen samples of colon adenomas ( 3 patients) and carcinomas (5 patients), and LC-MS/MS was used for protein identification and label-free quantification. The results were combined with a database search to generate a list of 106 proteins with nuclear annotations and at least a three-fold expression difference. Here, gene names from Table 2 of Knol et al. (2014) were converted to UniProt IDs.

UNS +14: Uzozie et al. (2014) analyzed 30 samples of colorectal adenomas and paired normal mucosa using iTRAQ labeling, OFFGEL electrophoresis and LC-MS/MS. 111 proteins with expression fold changes $\left(\log _{2}\right)$ at least $+/-0.5$ and statistical significance threshold $q<0.02$ that were also quantified in cell-line experiments were classified as "epithelial cell signature proteins". UniProt IDs were taken from Table III of Uzozie et al. (2014).

WKP +14: de Wit et al. (2014) analyzed the secretome of paired CRC and normal tissue from 4 patients, adopting a five-fold enrichment cutoff for identification of candidate biomarkers. Here, the list of proteins from Supplementary Table 1 of de Wit et al. (2014) was filtered to include those with at least five-fold greater or lower abundance in CRC samples and $p<0.05$. Two proteins listed as "Unmapped by Ingenuity" were removed, and gene names were converted to UniProt IDs using the UniProt mapping tool.

STK+15: Sethi et al. (2015) analyzed the membrane-enriched proteome from tumor and adjacent normal tissues from 8 patients using label-free nano-LC-MS/MS to identify 184 proteins with a fold change $>1.5$ and $p$-value $<0.05$. Here, protein identifiers from Supporting Table 2 of Sethi et al. (2015) were used to find the corresponding UniProt IDs.

WDO+15: Wiśniewski et al. (2015) analyzed 8 matched formalin-fixed and paraffin-embedded (FFPE) samples of normal tissue (N) and adenocarcinoma (C) and 16 nonmatched adenoma samples (A) using LC-MS to identify 2300 (N/A), 1780 (A/C) and 2161 (N/C) up- or down-regulated proteins at $p<0.05$. The list of proteins used in this study includes only those marked as having a significant change in SI Table 3 of Wiśniewski et al. (2015).

LPL+16: Li et al. (2016) used iTRAQ and 2D LC-MS/MS to analyze pooled 
samples of stroma purified by laser capture microdissection (LCM) from 5 cases of non-neoplastic colonic mucosa (NC), 8 of adenomatous colon polyps (AD), 5 of colon carcinoma in situ (CIS) and 9 of invasive colonic carcinoma (ICC). A total of 222 differentially expressed proteins between NC and other stages were identified. Here, gene symbols from Supplementary Table S3 of Li et al. (2016) were converted to UniProt IDs using the UniProt mapping tool.

PHL+16: Peng et al. (2016) used iTRAQ 2D LC-MS/MS to analyze pooled samples from 5 cases of normal colonic mucosa (NC), 8 of adenoma (AD), 5 of carcinoma in situ (CIS) and 9 of invasive colorectal cancer (ICC). A total of 326 proteins with differential expression between two successive stages (and, for CIS and ICC, also differentially expressed with respect to NC) were detected. The list of proteins used in this study was generated by converting the gene names in Supplementary Table 4 of Peng et al. (2016) to UniProt IDs using the UniProt mapping tool.

\subsection{Basis I}

To formulate a thermodynamic description of a chemically reacting system, an important choice must be made regarding the basis species used to describe the system. The basis species, like thermodynamic components, are a minimum number of chemical formula units that can be linearly combined to generate the composition of any chemical species in the system of interest. Stated differently, any species can be formed by combining the components, but components can not be used to form other components (VanBriesen and Rittmann, 1999). Within these constraints, any specific choice of a basis is theoretically permissible. In making the choice of components, convenience (Gibbs, 1875), ease of interpretation and relationship with measurable variables, as well as availability of thermodynamic data (e.g. Helgeson, 1970), and kinetic favorability (May and Murray, 2001) are other useful considerations. Once the basis species are chosen, the stoichiometric coefficients in the formation reaction for any chemical species are algebraically determined.

Following previous studies (e.g. Dick, 2008), the basis species initially chosen here are $\mathrm{CO}_{2}, \mathrm{H}_{2} \mathrm{O}, \mathrm{NH}_{3}, \mathrm{H}_{2} \mathrm{~S}$ and $\mathrm{O}_{2}$ (Basis I). The reaction representing the overall formation from these basis species of a protein having the formula $\mathrm{C}_{c} \mathrm{H}_{h} \mathrm{~N}_{n} \mathrm{O}_{o} \mathrm{~S}_{s}$ is

$$
c \mathrm{CO}_{2}+n \mathrm{NH}_{3}+s \mathrm{H}_{2} \mathrm{~S}+n_{\mathrm{H}_{2} \mathrm{O}} \mathrm{H}_{2} \mathrm{O}+n_{\mathrm{O}_{2}} \mathrm{O}_{2} \rightarrow \mathrm{C}_{c} \mathrm{H}_{h} \mathrm{~N}_{n} \mathrm{O}_{o} \mathrm{~S}_{s}
$$

where $n_{\mathrm{H}_{2} \mathrm{O}}=(h-3 n-2 s) / 2$ and $n_{\mathrm{O}_{2}}=\left(o-2 c-n_{\mathrm{H}_{2} \mathrm{O}}\right) / 2$. Dividing $n_{\mathrm{H}_{2} \mathrm{O}}$ by the length of the protein gives the water demand per residue $\left(\bar{n}_{\mathrm{H}_{2} \mathrm{O}}\right)$, which is used here because proteins in the comparisons generally have different sequence lengths.

These or similar sets of inorganic species (such as $\mathrm{H}_{2}$ instead of $\mathrm{O}_{2}$ ) are often used in studying reaction energetics in geobiochemistry (e.g. Shock and Canovas, 2010). However, as seen in Fig. $1 \mathrm{~A}$ and $\mathrm{B}$, there is a high correlation between $Z_{\mathrm{C}}$ of protein molecules and $\bar{n}_{\mathrm{H}_{2} \mathrm{O}}$ in the reactions to form the proteins from Basis I (note that the choice of basis species affects only $\bar{n}_{\mathrm{H}_{2} \mathrm{O}}$ and not $Z_{\mathrm{C}}$ ). Because of this stoichiometric interdependence, changes in either redox or hydration potential, while holding the chemical potentials of the remaining basis species constant, have correlated effects on the energetics of chemical transformations (see Section 3.6 below). A different set of 

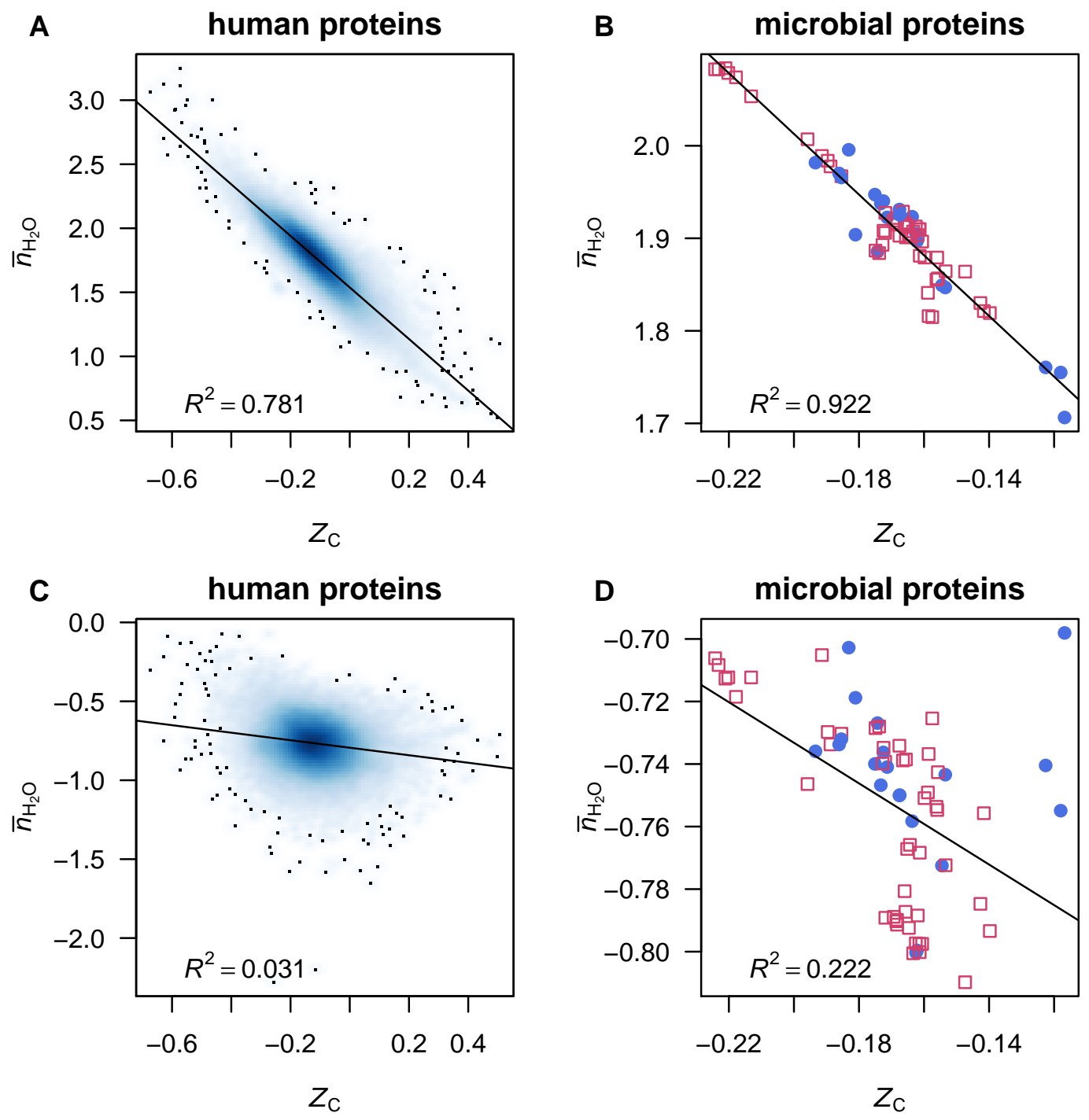

Figure 1. Scatterplots of average oxidation state of carbon $\left(Z_{C}\right)$ and water demand per residue $\left(\bar{n}_{\mathrm{H}_{2} \mathrm{O}}\right)$. Data are plotted for $(\mathrm{A}, \mathrm{C})$ individual human proteins and (B,D) mean composition of proteins from microbial genomes, with $\bar{n}_{\mathrm{H}_{2} \mathrm{O}}$ computed using $(\mathrm{A}, \mathrm{B})$ Basis I (Reaction R1) or (C,D) Basis II (Reaction R2). Linear least-squares fits and $R^{2}$ values are shown. In (A) and (C), the intensity of shading corresponds to density of points, produced using the smoothScatter () function of R graphics ( $R$ Core Team, 2016). The label in plot (A) identifies a particular protein, MUC1, which is used for the example calculations (see Reactions R3 and R4).

basis species can be chosen that reduces this correlation and affords a more informative description of the compositional changes in proteomic transformations.

\subsection{Basis II}

In this exploratory study, we restrict attention to at most two variables, with the implication that the others are held constant. In a subcellular setting, assuming that the chemical potentials of $\mathrm{CO}_{2}, \mathrm{NH}_{3}$ and $\mathrm{H}_{2} \mathrm{~S}$ do not change during a proteomic 
transformation, as implied by varying the chemical potentials of $\mathrm{O}_{2}$ and $\mathrm{H}_{2} \mathrm{O}$ in Basis $\mathrm{I}$, may be less appropriate than assuming constant chemical potentials of more complex metabolites. In thermodynamic models for systems of proteins, constant chemical activities of chemical components having the compositions of amino acids might be a reasonable provision.

Although 11403 -way combinations can be made of the 20 common proteinogenic amino acids, only 324 of the combinations contain cysteine and/or methionine (one of these is required to provide sulfur), and of these only 300, when combined with $\mathrm{O}_{2}$ and $\mathrm{H}_{2} \mathrm{O}$, are compositionally nondegenerate. The slope, intercept and $R^{2}$ of the linear least-squares fits between $Z_{\mathrm{C}}$ and $\bar{n}_{\mathrm{H}_{2} \mathrm{O}}$ using each possible basis containing $\mathrm{O}_{2}, \mathrm{H}_{2} \mathrm{O}$ and three amino acids are listed in file AAbas is. Csv in Dataset S1. Many of these combinations have lower $R^{2}$ and lower slopes than found for Basis I (Fig. 1A, B), indicating a decreased correlation. From those with a lower correlation, but not the lowest, the basis including cysteine (Cys), glutamic acid (Glu), glutamine (Gln), $\mathrm{O}_{2}$ and $\mathrm{H}_{2} \mathrm{O}$ (Basis II) has been selected for use in this study. The scatter plots and fits between $Z_{\mathrm{C}}$ and $\bar{n}_{\mathrm{H}_{2} \mathrm{O}}$ using Basis II are shown in Fig. $1 \mathrm{C}$ and D.

A secondary consideration in choosing this basis instead of others with even lower $R^{2}$ is the centrality of glutamine and glutamic acid in many metabolic pathways (e.g. DeBerardinis and Cheng, 2010). Accordingly, these amino acids may be kinetically more reactive than others in pathways of protein synthesis and degradation. The presence of side chains derived from cysteine and glutamic acid in the abundant glutathione molecule (GSH), associated with redox homeostasis, is also suggestive of a central metabolic requirement for these amino acids. Again, it must be stressed that the current provisional choice of basis species is neither uniquely determined nor necessarily optimal for a thermodynamic description of any particular system. More experience with thermodynamic modeling and better biochemical intuition will likely provide reasons to refine these calculations using a different basis, perhaps including metabolites other than amino acids.

A general formation reaction using Basis II is

$$
\begin{aligned}
n_{\mathrm{Cys}} \mathrm{C}_{3} \mathrm{H}_{7} \mathrm{NO}_{2} \mathrm{~S}+n_{\mathrm{Glu}} \mathrm{C}_{5} \mathrm{H}_{9} \mathrm{NO}_{4}+ & n_{\mathrm{Gln}_{5} \mathrm{C}_{5} \mathrm{H}_{10} \mathrm{~N}_{2} \mathrm{O}_{3}} \\
& +n_{\mathrm{H}_{2} \mathrm{O}} \mathrm{H}_{2} \mathrm{O}+n_{\mathrm{O}_{2}} \mathrm{O}_{2} \rightarrow \mathrm{C}_{c} \mathrm{H}_{h} \mathrm{~N}_{n} \mathrm{O}_{o} \mathrm{~S}_{s}
\end{aligned}
$$

where the reaction coefficients $\left(n_{\mathrm{Cys}}, n_{\mathrm{Glu}}, n_{\mathrm{Gln}}, n_{\mathrm{H}_{2} \mathrm{O}}\right.$ and $\left.n_{\mathrm{O}_{2}}\right)$ can be obtained by solving

$$
\left[\begin{array}{ccccc}
3 & 5 & 5 & 0 & 0 \\
7 & 9 & 10 & 2 & 0 \\
1 & 1 & 2 & 0 & 0 \\
2 & 4 & 3 & 1 & 2 \\
1 & 0 & 0 & 0 & 0
\end{array}\right] \times\left[\begin{array}{c}
n_{\mathrm{Cys}} \\
n_{\mathrm{Glu}} \\
n_{\mathrm{Gln}} \\
n_{\mathrm{H}_{2} \mathrm{O}} \\
n_{\mathrm{O}_{2}}
\end{array}\right]=\left[\begin{array}{c}
c \\
h \\
n \\
o \\
s
\end{array}\right]
$$

Although the definition of basis species requires that they are themselves compositionally nondegenerate, the matrix equation emphasizes the interdependence of the stoichiometric reaction coefficients. A consequence of this multiple dependence is that single variables such as $n_{\mathrm{O}_{2}}$ and $n_{\mathrm{H}_{2} \mathrm{O}}$ are not simple variables, but are influenced 
by both the chemical composition of the protein and the choice of basis species used to describe the system.

The combination of molecules shown in Reaction R2 does not represent the actual mechanism of synthesis of the proteins. Instead, reactions such as this account for mass-conservation requirements and permit the subsequent generation of thermodynamic models for the potential for formation of different proteins as a function of system parameters (i.e. chemical potentials of $\mathrm{O}_{2}$ and $\mathrm{H}_{2} \mathrm{O}$ ).

As an example of a specific calculation, consider the following reaction for MUC1, a chromatin-binding protein that is highly up-expressed in CRC cells (Knol et al., 2014).

$$
\begin{array}{r}
7 \mathrm{C}_{3} \mathrm{H}_{7} \mathrm{NO}_{2} \mathrm{~S}+535.6 \mathrm{C}_{5} \mathrm{H}_{9} \mathrm{NO}_{4}+515.2 \mathrm{C}_{5} \mathrm{H}_{10} \mathrm{~N}_{2} \mathrm{O}_{3} \rightarrow \\
\mathrm{C}_{5275} \mathrm{H}_{8231} \mathrm{~N}_{1573} \mathrm{O}_{1762} \mathrm{~S}_{7}+895.2 \mathrm{H}_{2} \mathrm{O}+522.4 \mathrm{O}_{2}
\end{array}
$$

As with the other reactions shown above, this reaction is not a mechanism, but represents the stoichiometric requirements for the formation from the basis species of one mole of the protein. Water is released in Reaction R3, so the water demand $\left(n_{\mathrm{H}_{2} \mathrm{O}}\right)$ is negative. The length of this protein is 1255 amino acid residues, giving the water demand per residue, $\bar{n}_{\mathrm{H}_{2} \mathrm{O}}=-895.2 / 1255=-0.71$. The average oxidation state of carbon $\left(Z_{\mathrm{C}}\right)$ in MUC1, which does not depend on the choice of basis species, is 0.005 (Eq. 1). The value of $Z_{\mathrm{C}}$ indicates that MUC1 is a relatively highly oxidized protein, while its $\bar{n}_{\mathrm{H}_{2} \mathrm{O}}$ places it near the median water demand for up-expressed proteins in cancer in this dataset (see Fig. 2A below).

\subsection{Thermodynamic calculations}

Standard molal thermodynamic properties of the amino acids and unfolded proteins estimated using amino acid group additivity were calculated as described by Dick et al. (2006), taking account of updated values for the methionine sidechain group (LaRowe and Dick, 2012). In this study, the Gibbs energies of hypothetically non-ionized proteins were used, and calculations were carried out at $37^{\circ} \mathrm{C}$ and 1 bar. The temperature dependence of standard Gibbs energies was calculated using the revised Helgeson-Kirkham-Flowers (HKF) equations of state (Helgeson et al., 1981; Tanger and Helgeson, 1988). Thermodynamic properties for $\mathrm{O}_{2}$ (gas) were calculated using data from Wagman et al. (1982) and the Maier-Kelley heat capacity function (Kelley, 1960). Properties of liquid $\mathrm{H}_{2} \mathrm{O}$ were calculated using data and extrapolations coded in Fortran subroutines from the SUPCRT92 package (Johnson et al., 1992), as provided in the CHNOSZ package (Dick, 2008).

Chemical affinities of reactions were calculated using activities of amino acids in the basis equal to $10^{-4}$, and activities of proteins equal to $1 /$ (protein length) (i.e., unit activity of amino acid residues). Continuing with the example of Reaction R3, an estimate of the standard Gibbs energy $\left(\Delta G_{f}^{\circ}\right)$ of the aqueous protein molecule (Dick et al., 2006; LaRowe and Dick, 2012) at $37^{\circ} \mathrm{C}$ is $-40974 \mathrm{kcal} / \mathrm{mol}$; combined with the standard Gibbs energies of the basis species, this give a standard Gibbs energy of reaction $\left(\Delta G_{r}^{\circ}\right)$ equal to $66889 \mathrm{kcal} / \mathrm{mol}$. At $\log a_{\mathrm{H}_{2} \mathrm{O}}=0$ and $\log f_{\mathrm{O}_{2}}=-65$, with activities of the amino acid basis species equal to $10^{-4}$, the overall Gibbs energy $\left(\Delta G_{r}\right)$ is $24701 \mathrm{kcal} / \mathrm{mol}$. The negative of this value is the chemical affinity $(A)$ of the reaction. 
The per-residue chemical affinity for formation of protein MUC1 in the stated conditions is $-19.7 \mathrm{kcal} / \mathrm{mol}$. (This calculation can be reproduced using the function reaction ( ) in file plot. $\mathrm{R}$ in Dataset $\mathrm{S} 1$. )

In a given system, proteins with higher (more positive) chemical affinity are relatively energetically stabilized, and theoretically have a higher propensity to be formed. Therefore, the differences in affinities reflect not only the amino acid compositions of the protein molecules but also the potential for local environmental conditions to influence the relative abundances of proteins.

\subsection{Weighted rank difference}

The contours on relative stability diagrams for the groups of differentially expressed proteins (see Fig. 6 below) depict the weighted rank differences of chemical affinities of formation of proteins. To illustrate this calculation, consider a hypothetical system composed of 3 proteins with higher expression in cancer (C) and 4 with higher expression in normal samples (down-expressed in cancer, i.e. having higher expression in a healthy state) $(\mathrm{H})$. Suppose that under one set of conditions (i.e. specified $\log a_{\mathrm{H}_{2} \mathrm{O}}$ and $\log f_{\mathrm{O}_{2}}$ ), the per-residue affinities of the proteins give the following ranking in ascending order (I):

$$
\begin{array}{ccccccc}
\mathrm{C} & \mathrm{C} & \mathrm{C} & \mathrm{H} & \mathrm{H} & \mathrm{H} & \mathrm{H} \\
1 & 2 & 3 & 4 & 5 & 6 & 7
\end{array}
$$

This gives as the sum of ranks for up-expressed (C) proteins $\sum r_{\mathrm{C}}=6$, and for down-expressed $(\mathrm{H})$ proteins $\sum r_{\mathrm{H}}=22$. The difference in sum of ranks is $\Delta r_{\mathrm{C}-\mathrm{H}}=-16$; the negative value is associated with a higher rank sum for the down-expressed proteins, indicating that these as a group are more stable than the down-expressed proteins. In a second set of conditions, we might have (II):

$$
\begin{array}{ccccccc}
\mathrm{H} & \mathrm{H} & \mathrm{H} & \mathrm{H} & \mathrm{C} & \mathrm{C} & \mathrm{C} \\
1 & 2 & 3 & 4 & 5 & 6 & 7
\end{array}
$$

Here, the difference of rank sums is $\Delta r_{\mathrm{C}-\mathrm{H}}=18-10=8$.

For systems where the numbers of proteins in the two groups are equal, the maximum possible differences in rank sums would have equal absolute values, but that is not the case in this and other systems having unequal numbers of up- and down-expressed proteins. To characterize these datasets, the weighted rank-sum difference can be calculated using

$$
\Delta \bar{r}=2\left(\frac{n_{\mathrm{H}}}{n} \sum r_{\mathrm{C}}-\frac{n_{\mathrm{C}}}{n} \sum r_{\mathrm{H}}\right)
$$

where $n_{\mathrm{H}}, n_{\mathrm{C}}$ and $n$ are the numbers of down-expressed, up-expressed, and total proteins in the comparison. In the example here, we have $n_{\mathrm{H}} / n=4 / 7$ and $n_{\mathrm{C}} / n=3 / 7$. Eq. (3) then gives $\Delta \bar{r}=-12$ and $\Delta \bar{r}=12$, respectively, for conditions (I) and (II) above, showing equal weighted rank-sum differences for the two extreme rankings.

We can also consider a situation where the ranks of the proteins are evenly distributed: 

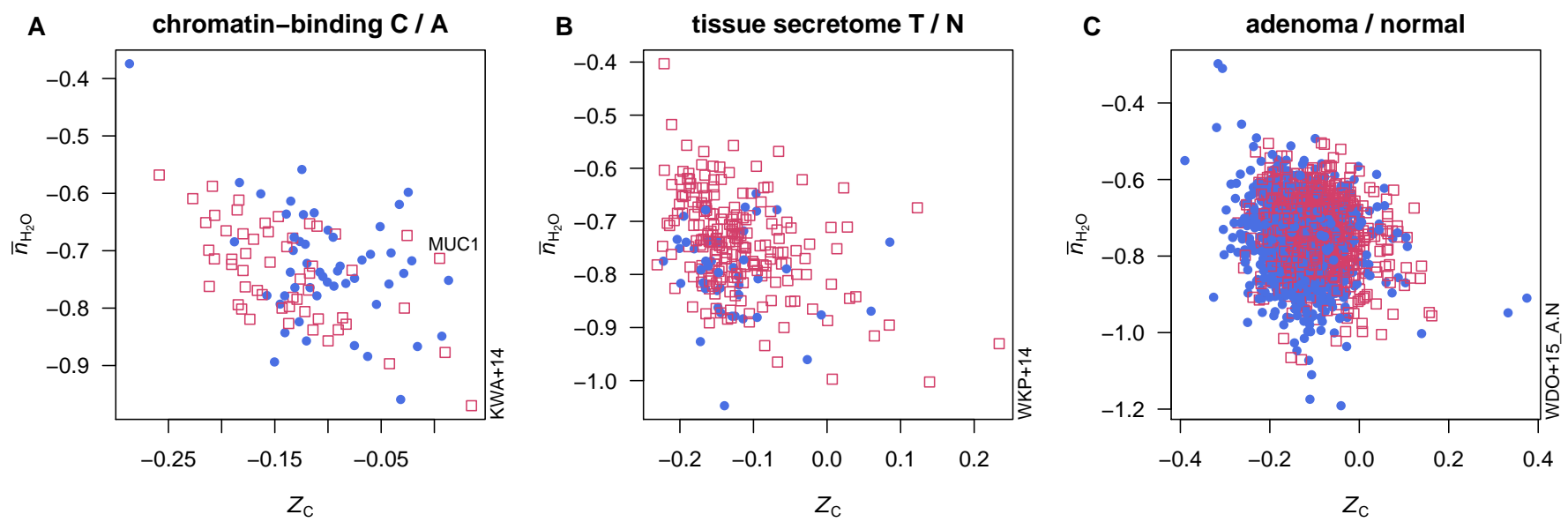

Figure 2. Average oxidation state of carbon $\left(Z_{\mathrm{C}}\right)$ and water demand per residue $\left(\bar{n}_{\mathrm{H}_{2} \mathrm{O}}\right)$ for proteins in selected datasets. Open red squares represent proteins enriched in tumors or more advanced cancer stages, and filled blue circles represent proteins enriched in normal tissue or less advanced cancer stages.

$$
\begin{array}{ccccccc}
\mathrm{H} & \mathrm{C} & \mathrm{H} & \mathrm{C} & \mathrm{H} & \mathrm{C} & \mathrm{H} \\
1 & 2 & 3 & 4 & 5 & 6 & 7
\end{array}
$$

Here the absolute difference of rank sums is $\Delta r_{\mathrm{C}-\mathrm{H}}=12-16=-4$, but the weighted rank-sum difference is $\Delta \bar{r}=0$. The zero value for an even distribution and the opposite values for the two extremes demonstrate the applicability of this weighting scheme.

\subsection{Software and data availability}

All statistical and thermodynamic calculations were performed using R (R Core Team, 2016). Thermodynamic calculations were carried out using R package CHNOSZ (Dick, 2008). Effect sizes (see below) were calculated using R package orddom (Rogmann, 2013). Figures were generated using CHNOSZ and graphical functions available in $R$ together with the R package colorspace (Ihaka et al., 2015) for constructing an HCL-based color palette (Zeileis et al., 2009). With the mentioned packages installed, Table 1 and the figures in this paper can be reproduced using the code (plot.R) and data files (*.CSV) in Dataset S1.

\section{RESULTS}

\subsection{Compositional comparisons of human proteins}

Comparisons of proteome composition in terms of average oxidation state of carbon $\left(Z_{\mathrm{C}}\right)$ and water demand per residue $\left(\bar{n}_{\mathrm{H}_{2} \mathrm{O}}\right)$ are presented in Fig. 2 and Table 1. Fig. 2 shows scatterplots of individual protein compositions for proteomes in three representative studies. Each of these exhibits a strongly differential trend in $Z_{\mathrm{C}}$ or $\bar{n}_{\mathrm{H}_{2} \mathrm{O}}$ that can be visually identified. In Fig. 2A, chromatin-binding proteins highly expressed in carcinoma (Knol et al., 2014) as a group exhibit a lower $Z_{C}$ than those found to be more abundant in adenoma. In Fig. 2B, proteins relatively highly expressed in epithelial cells in adenoma (Uzozie et al., 2014) tend to have higher $\bar{n}_{\mathrm{H}_{2} \mathrm{O}}$ than the proteins more 
highly expressed in paired normal tissues. Differentially expressed proteins between adenoma and normal tissue identified in a recent deep-proteome analysis (Wiśniewski et al., 2015) are compared in Fig. 2C, showing that proteins up-expressed in adenoma are relatively oxidized (i.e. have higher $Z_{C}$ ).

In order to quantify these differences, Table 1 shows the numbers of proteins in each comparison ( $n_{1}$ for normal or less advanced cancer stage; $n_{2}$ for tumor or more advanced cancer stage), differences of means (MD), common language effect size as percentages (ES), and $p$-values calculated using the Wilcoxon rank sum test. This non-parametric test is suitable for data which may not be normally distributed. For a given experiment, the common language effect size, or probability of superiority, describes the probability that $Z_{\mathrm{C}}$ or $\bar{n}_{\mathrm{H}_{2} \mathrm{O}}$ of a protein is higher in the cancer group than in the normal group. That is, percent values of the ES greater than (or less than) 50 indicate a greater proportion of pairwise higher (or lower) $Z_{\mathrm{C}}$ or $\bar{n}_{\mathrm{H}_{2} \mathrm{O}}$ of proteins in the $n_{2}$ compared to $n_{1}$ groups. The ES and $p$-value are used here to allow for a subjective assessment of the compositional differences. ES values $\geq 60$ or $\leq 40$ and $p$-values $<$ 0.05 are highlighted in the table. The corresponding mean differences are underlined for $p<0.05$, or bolded if ES is also $\geq 60$ or $\leq 40$. These cutoffs highlight datasets with the largest and most significant differences in $Z_{\mathrm{C}}$ and $\bar{n}_{\mathrm{H}_{2} \mathrm{O}}$. Mean and median values of $Z_{\mathrm{C}}$ and $\bar{n}_{\mathrm{H}_{2} \mathrm{O}}$ are given in file summary . CSV in Dataset S1.

Counting the underlined and bolded MD values in Table 1, the number of datasets with a significant difference in $Z_{C}(18)$ is greater than those with a significant difference in $\bar{n}_{\mathrm{H}_{2} \mathrm{O}}(10)$. Of the 10 unique studies yielding at least one dataset with a significant difference in $Z_{C}$ in a comparison with normal tissue, 8 exhibit a higher mean value in adenoma or carcinoma compared to normal tissue. One of the other studies (Besson et al., 2011) has datasets with higher mean $Z_{C}$ in proteins up-expressed in adenoma, but lower mean $\mathrm{Z}_{\mathrm{C}}$ in proteins up-expressed in stage II and III carcinoma, compared to normal tissue. A second study, which analyzed proteins in stromal cells (Li et al., 2016), shows a significantly lower $Z_{C}$ in adenoma compared to normal tissue.

Most of the studies analyzed proteins in whole or microdissected tissue, but two datasets in studies from the same laboratory represent the nuclear matrix or chromatin-binding fraction (Albrethsen et al., 2010; Knol et al., 2014). These two datasets give lower mean $Z_{C}$ of proteins more highly expressed in carcinoma than adenoma. One other dataset has a lower mean $Z_{\mathrm{C}}$ of proteins up-expressed in carcinoma compared to adenoma (Wiśniewski et al., 2015), and one has a higher mean value (Mikula et al., 2011).

The datasets with a significant difference in $\bar{n}_{\mathrm{H}_{2} \mathrm{O}}$ all show higher mean values for proteins in adenoma (5 datasets) or carcinoma (3 datasets) compared to normal tissue, up- expressed compared to down-expressed serum biomarker candidates (Jimenez et al., 2010), and secreted proteins of tumor tissue compared to normal tissue (de Wit et al., 2014). Interestingly, none of the datasets with a significant difference in $\bar{n}_{\mathrm{H}_{2} \mathrm{O}}$ corresponds to a carcinoma / adenoma comparison.

Natural variability inherent in the heterogeneity of tumors, as well as differences in experimental design and technical analysis, may underlie the opposite trends in $Z_{C}$ between some datasets that compare the same stages of cancer. However, there is a preponderance of datasets with higher values of $Z_{\mathrm{C}}$ and $\bar{n}_{\mathrm{H}_{2} \mathrm{O}}$ for the proteins up-expressed in adenoma or carcinoma compared to normal tissue. 
Table 1. Summary of compositional comparisons for human proteins. Mean differences (MD), percent values of common language effect size (ES), and $p$-values are shown for comparisons between groups of proteins reported to have higher abundance in normal $\left(n_{1}\right)$ or cancer $\left(n_{2}\right)$ tissue (or less advanced or more advanced cancer stages, respectively). The textual descriptions are written such that the ordering around the slash (“/”) corresponds to $n_{2} / n_{1}$. Abbreviations: T / N (tumor / normal), C / A (carcinoma / adenoma). References and specific abbreviations used in the descriptions are given in Section 2.1.

\begin{tabular}{|c|c|c|c|c|c|c|c|c|}
\hline \multirow[b]{2}{*}{ Reference (Description) } & \multirow[b]{2}{*}{$n_{1}$} & \multirow[b]{2}{*}{$n_{2}$} & \multicolumn{3}{|c|}{$Z_{\mathrm{C}}$} & \multicolumn{3}{|c|}{$\bar{n}_{\mathrm{H}_{2} \mathrm{O}}$} \\
\hline & & & MD & $\mathrm{ES}$ & $p$-value & MD & ES & $p$-value \\
\hline WTK+08 (T / N) & 57 & 70 & 0.018 & 55 & $3 e-01$ & 0.006 & 52 & $7 e-01$ \\
\hline $\mathrm{AKP}+10(\mathrm{CRC}$ nuclear matrix $\mathrm{C} / \mathrm{A})$ & 101 & 28 & -0.012 & 47 & $7 e-01$ & -0.009 & 48 & $8 \mathrm{e}-01$ \\
\hline AKP +10 (CIN nuclear matrix C / A) & 87 & 81 & -0.031 & 40 & 3e-02 & 0.006 & 48 & $7 e-01$ \\
\hline $\mathrm{AKP}+10(\mathrm{MIN}$ nuclear matrix C / A) & 157 & 76 & -0.002 & 52 & $7 e-01$ & -0.013 & 45 & $3 e-01$ \\
\hline JKMF 10 (serum biomarkers up / down) & 43 & 56 & -0.007 & 46 & $5 e-01$ & 0.056 & 67 & 4e-03 \\
\hline $\mathrm{XZC}+10($ stage I / normal $)$ & 48 & 166 & 0.009 & 52 & $7 e-01$ & 0.026 & 56 & $2 \mathrm{e}-01$ \\
\hline XZC+10 (stage II / normal) & 77 & 321 & 0.022 & 60 & $6 e-03$ & 0.018 & 54 & $3 e-01$ \\
\hline ZYS + 10 (microdissected T/ N) & 60 & 57 & 0.019 & 58 & $1 \mathrm{e}-01$ & 0.022 & 58 & $1 \mathrm{e}-01$ \\
\hline BPV+11 (adenoma / normal) & 71 & 92 & -0.023 & 40 & $4 e-02$ & 0.004 & 49 & $8 \mathrm{e}-01$ \\
\hline BPV+11 (stage I / normal) & 109 & 72 & -0.007 & 47 & $5 e-01$ & 0.005 & 50 & $9 \mathrm{e}-01$ \\
\hline BPV+11 (stage II / normal) & 164 & 140 & $\mathbf{0 . 0 3 1}$ & 62 & 3e-04 & 0.006 & 51 & $7 e-01$ \\
\hline BPV+11 (stage III / normal) & 63 & 131 & 0.025 & 62 & 9e-03 & -0.005 & 47 & $5 e-01$ \\
\hline BPV+11 (stage IV / normal) & 42 & 26 & -0.010 & 44 & $4 \mathrm{e}-01$ & 0.005 & 52 & $8 \mathrm{e}-01$ \\
\hline $\mathrm{JCF}+11(\mathrm{~T} / \mathrm{N})$ & 72 & 45 & $\mathbf{0 . 0 3 2}$ & 63 & $2 e-02$ & -0.003 & 49 & $8 \mathrm{e}-01$ \\
\hline MRK+11 (adenoma / normal) & 335 & 288 & 0.011 & 54 & $1 \mathrm{e}-01$ & 0.058 & 68 & 2e-15 \\
\hline MRK +11 (adenocarcinoma / adenoma) & 373 & 257 & 0.034 & 65 & 1e-10 & -0.009 & 47 & $1 \mathrm{e}-01$ \\
\hline MRK+11 (adenocarcinoma / normal) & 351 & 232 & 0.034 & 63 & 4e-08 & $\mathbf{0 . 0 3 5}$ & 61 & 8e-06 \\
\hline KKL+12 (poor / good prognosis) & 75 & 61 & 0.026 & 64 & $5 e-03$ & -0.002 & 48 & $8 \mathrm{e}-01$ \\
\hline KYK+12 (MSS-type T / N) & 73 & 175 & 0.024 & 61 & $9 e-03$ & 0.023 & 56 & $1 \mathrm{e}-01$ \\
\hline $\mathrm{WOD}+12(\mathrm{~T} / \mathrm{N})$ & 79 & 677 & 0.016 & 54 & $2 \mathrm{e}-01$ & 0.027 & 58 & 2e-02 \\
\hline YLZ+12 (conditioned media T / N) & 55 & 68 & 0.024 & 61 & $4 e-02$ & 0.009 & 54 & $5 e-01$ \\
\hline MCZ+13 (stromal T / N) & 33 & 37 & 0.047 & 74 & 5e-04 & -0.034 & 42 & $2 \mathrm{e}-01$ \\
\hline KWA +1 4 (chromatin-binding C / A) & 51 & 55 & -0.039 & 29 & 2e-04 & -0.010 & 48 & $7 e-01$ \\
\hline UNS +14 (epithelial adenoma / normal) & 58 & 65 & 0.001 & 49 & $8 \mathrm{e}-01$ & $\mathbf{0 . 0 3 2}$ & 61 & 4e-02 \\
\hline WKP +14 (tissue secretome T / N) & 44 & 210 & 0.006 & 53 & $6 e-01$ & 0.057 & 68 & 1e-04 \\
\hline STK+15 (membrane enriched T / N) & 113 & 66 & 0.005 & 52 & $6 e-01$ & 0.025 & 55 & $2 \mathrm{e}-01$ \\
\hline WDO +15 (adenoma / normal) & 1061 & 1254 & $\mathbf{0 . 0 3 0}$ & 64 & $7 e-33$ & 0.023 & 58 & $7 e-11$ \\
\hline WDO+15 (carcinoma / adenoma) & 772 & 1007 & $\underline{-0.013}$ & 42 & $2 e-08$ & $\overline{-0.003}$ & 50 & $7 \mathrm{e}-01$ \\
\hline WDO+15 (carcinoma / normal) & 879 & 1281 & 0.014 & 57 & $9 e-08$ & 0.024 & 58 & 1e-10 \\
\hline LPL+16 (stromal AD / NC) & 123 & 75 & -0.039 & 32 & 2e-05 & $\mathbf{0 . 0 3 7}$ & 60 & 2e-02 \\
\hline LP L+1 6 (stromal CIS / NC) & 125 & 60 & -0.007 & 46 & $4 \mathrm{e}-01$ & -0.001 & 52 & $7 e-01$ \\
\hline LPL+16 (stromal ICC / NC) & 99 & 75 & 0.001 & 47 & $6 e-01$ & -0.021 & 48 & $7 \mathrm{e}-01$ \\
\hline PHL+16 (AD / NC) & 113 & 86 & 0.011 & 54 & $4 \mathrm{e}-01$ & $\mathbf{0 . 0 3 7}$ & 60 & 2e-02 \\
\hline PHL+1 6 (CIS / NC) & 169 & 138 & 0.019 & 59 & $5 e-03$ & 0.001 & 49 & $7 \mathrm{e}-01$ \\
\hline PHL+16 (ICC / NC) & 129 & 100 & 0.016 & 57 & $6 e-02$ & -0.007 & 46 & $3 e-01$ \\
\hline
\end{tabular}


Table 2. Microbial species selected as models for genera and co-abundance groups that differ between CRC and healthy patients.

\begin{tabular}{|c|c|c|c|c|}
\hline Phylum & Species & Abbrv. & Bioproject & Refs. \\
\hline \multicolumn{5}{|c|}{ Model species for genera significantly higher in healthy patients ${ }^{\mathbf{a}}$} \\
\hline Bacteroidetes & Bacteroides vulgatus ATCC 8482 & Bvu & PRJNA13378 & c \\
\hline Bacteroidetes & Bacteroides uniformis ATCC 8492 & Bun & PRJNA18195 & c \\
\hline Firmicutes & Roseburia intestinalis L1-82 (DSM 14610) & Rin & PRJNA30005 & d \\
\hline Bacteroidetes & Alistipes indistinctus YIT 12060 & Ain & PRJNA46373 & c \\
\hline Firmicutes & Eubacterium rectale ATCC 33656 & Ere & PRJNA29071 & e \\
\hline Proteobacteria & Parasutterella excrementihominis YIT 11859 & Pex & PRJNA48497 & f \\
\hline \multicolumn{5}{|c|}{ Model species for genera significantly higher in CRC patients ${ }^{\mathbf{a}}$} \\
\hline Bacteroidetes & Porphyromonas gingivalis W83 & Pgi & PRJNA48 & g \\
\hline Proteobacteria & Escherichia coli $\mathrm{NC101}$ & Eco & PRJNA47121 & $\mathbf{c , h}$ \\
\hline Firmicutes & Enterococcus faecalis V583 & Efa & PRJNA57669 & c \\
\hline Firmicutes & Streptococcus infantarius ATCC BAA-102 & Sin & PRJNA20527 & i \\
\hline Firmicutes & Peptostreptococcus stomatis DSM 17678 & Pst & PRJNA34073 & $\mathbf{j}$ \\
\hline Bacteroidetes & Bacteroides fragilis $\mathrm{YCH} 46$ & Bfr & PRJNA58195 & g \\
\hline \multicolumn{5}{|c|}{ Model species for protective co-abundance groups ${ }^{\mathbf{b}}$} \\
\hline Actinobacteria & Bifidobacterium longum NCC2705 & Blo & PRJNA57939 & $\mathbf{g}, \mathbf{k}$ \\
\hline Firmicutes & Faecalibacterium prausnitzii SL3/3 & Fpr & PRJNA39151 & e,l \\
\hline \multicolumn{5}{|c|}{ Model species for pro-carcinogenic co-abundance groups ${ }^{\mathbf{b}}$} \\
\hline Fusobacteria & Fusobacterium nucleatum ATCC 23726 & Fnu & PRJNA49043 & $\mathbf{m}, \mathbf{n}$ \\
\hline Bacteroidetes & Prevotella copri DSM 18205 & Pco & PRJNA30025 & $\mathbf{k , o}$ \\
\hline Firmicutes & Coprobacillus sp. D7 & Csp & PRJNA32495 & h \\
\hline
\end{tabular}

a. Genus identification from Table 2 of Wang et al. (2012). Based on comments in Wang et al. (2012), Bacteroides is represented here by two species (B. vulgatus and B. uniformis) in healthy patients, and one species (B. fragilis) in CRC patients. b. Genus-level definition of co-abundance groups from Candela et al. (2014). c. Wang et al. (2012); species closely related to 16S rRNA-derived operational taxonomic units (OTUs; Figure 2 of Wang et al., 2012) or otherwise mentioned by those authors (E. faecalis). d. Duncan et al. (2002). e. Louis and Flint (2007). f. Nagai et al. (2009). g. Chen et al. (2012). h. Candela et al. (2014). i. Biarc et al. (2004). j. Zeller et al. (2014). k. Weir et al. (2013). l. Sokol et al. (2008). m. Castellarin et al. (2012). n. Kostic et al. (2012). o. cf. Chen et al. (2012); Candela et al. (2014) (more abundant in CRC patients); Weir et al. (2013) (more abundant in healthy subjects).

\subsection{Compositional comparisons of microbial proteins}

Summary data on microbial populations from four studies were selected for comparison here. First, in a study of 16S RNA of fecal microbiota, Wang et al. (2012) reported genera that are significantly increased or decreased in CRC compared to healthy patients. In order to compare the chemical compositions of the microbial populations, single species with sequenced genomes were chosen to represent each of these genera (see Table 2). Where possible, the species selected are those mentioned by Wang et al. (2012) as being significantly altered, or are species reported in other studies to be present in healthy or cancer states (see Table 2).

In the second study considered (Zeller et al., 2014), changes in the metagenomic abundance of fecal microbiota associated with CRC were analyzed for their potential as a biosignature for cancer detection. The species shown in Fig. 1A of Zeller et al. (2014) with a log odds ratio greater than 0.15 were selected for comparison, and are listed in 
Table 3. Species from a consensus microbial signature for CRC classification of fecal metagenomes (Zeller et al., 2014). Only species reported as having a log odds ratio larger than \pm 0.15 are listed here, together with strains and Bioproject IDs used as models in the present study.

\begin{tabular}{|c|c|c|c|}
\hline Species & Strain & Abbrv. & Bioproject \\
\hline \multicolumn{4}{|l|}{ Higher in CRC patients } \\
\hline Fusobacterium nucleatum subsp. vincentii & ATCC 49256 & Fnv & PRJNA1419 \\
\hline Fusobacterium nucleatum subsp. animalis & D11 & Fna & PRJNA32501 \\
\hline Peptostreptococcus stomatis & DSM 17678 & Pst & PRJNA34073 \\
\hline Porphyromonas asaccharolytica & DSM 20707 & Pas & PRJNA51745 \\
\hline Clostridium symbiosum & ATCC 14940 & Csy & PRJNA18183 \\
\hline Clostridium hylemonae & DSM 15053 & Chy & PRJNA30369 \\
\hline Lactobacillus salivarius & ATCC 11741 & Lsa & PRJNA31503 \\
\hline \multicolumn{4}{|l|}{ Higher in healthy patients } \\
\hline Clostridium scindens & ATCC 35704 & Csc & PRJNA18175 \\
\hline Eubacterium eligens & ATCC 27750 & Eel & PRJNA29073 \\
\hline Methanosphaera stadtmanae & DSM 3091 & Mst & PRJNA15579 \\
\hline Phascolarctobacterium succinatutens & YIT 12067 & Psu & PRJNA48505 \\
\hline unclassified Ruminococcus sp. & ATCC $29149(*)$ & Rsp & PRJNA18179 \\
\hline Streptococcus salivarius & SK126 & Ssa & PRJNA34091 \\
\hline
\end{tabular}

*R. gnavus

Table 4. Selected microbial species enriched or depleted in stool samples from cancer patients compared to healthy controls (Feng et al., 2015).

\begin{tabular}{llll}
\hline Enriched Species & Abbrv. & Depleted Species & Abbrv. \\
\hline Bacteroides dorei & Bdo & Actinomyces viscosus & Avi \\
Bacteroides ovatus & Bov & Bifidobacterium animalis & Ban \\
butyrate-producing bacterium SS3/4 & But & Clostridium sp. SS2/1 & Csp \\
Clostridium asparagiforme & Cas & Ruminococcus sp. 5_1_39BFAA & Rsp \\
Fusobacterium sp. oral taxon 370 & Fsp & Streptococcus mutans & Smu \\
Lachnospiraceae bacterium 3_1_57FAA_CT1 & L57 & Streptococcus thermophilus & Sth \\
Paraprevotella clara & Pcl & & \\
Peptostreptococcus stomatis & Pst & & \\
Ruminococcaceae bacterium D16 & Rba & & \\
\hline
\end{tabular}

Table 3. Zeller et al. (2014) found a strong enrichment of Fusobacterium in cancer, consistent with previous reports (Kostic et al., 2012; Castellarin et al., 2012). In a third study, Candela et al. (2014) reported the findings of a network analysis that identified 5 microbial "co-abundance groups" at the genus level. As before, single representative species were selected in this study, and are listed in Table 2. Except for the presence of Fusobacterium, the co-abundance groups show little genus-level overlap with community profiles derived from the previous two studies.

Finally, Table 4 lists the "best aligned strain" from Supplementary Dataset 5 of Feng et al. (2015) for all species shown there with negative enrichment in cancer, and for 

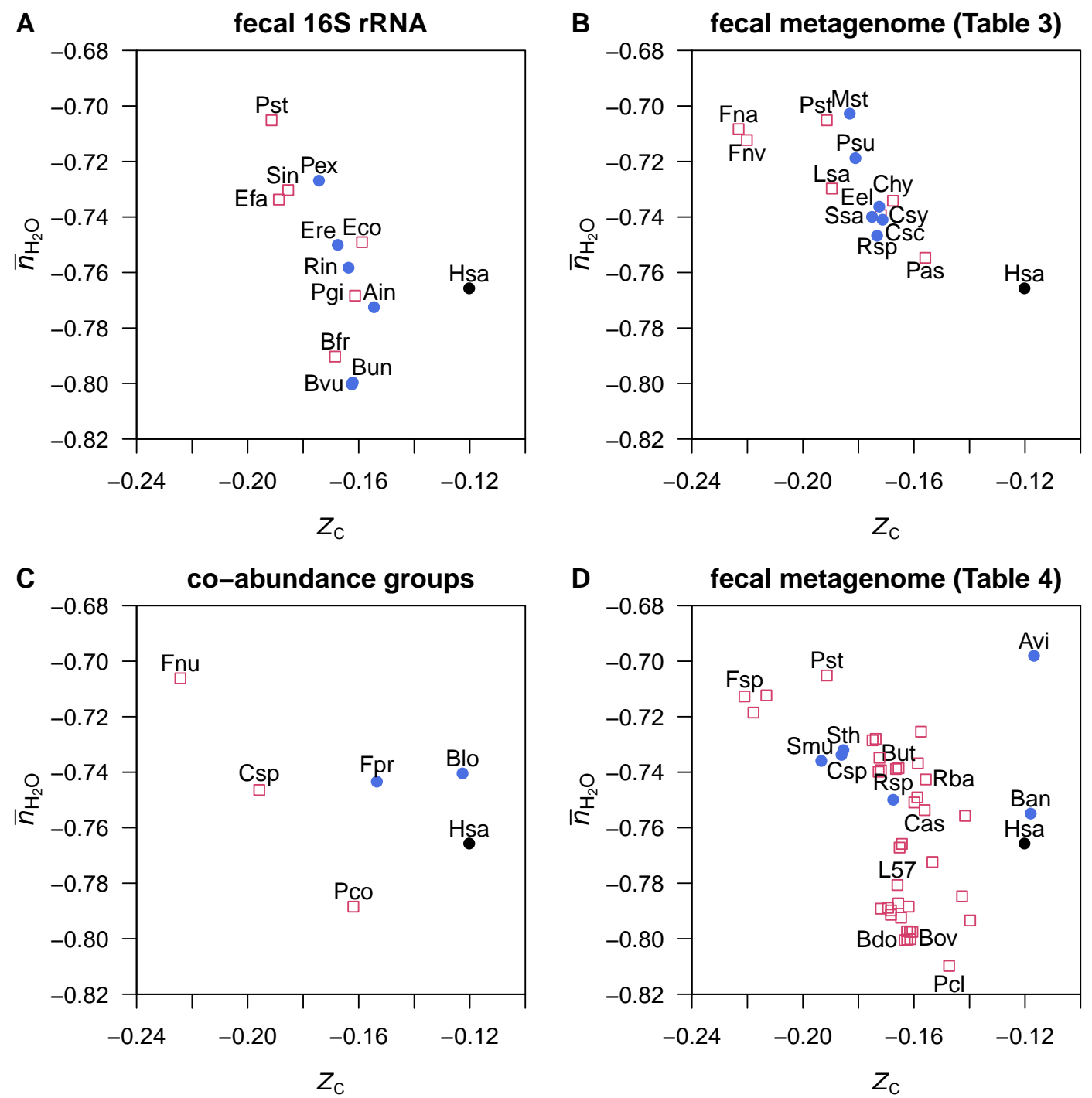

Figure 3. Average oxidation state of carbon $\left(Z_{C}\right)$ and water demand per residue $\left(\bar{n}_{\mathrm{H}_{2} \mathrm{O}}\right)$ for mean amino acid compositions of proteins in genomes of normal- and cancer-enriched microbes. Data are shown for representative species for (A) microbial genera identified in fecal 16s RNA (Wang et al., 2012; Table 2 top), (B) microbial signatures in fecal metagenomes (Zeller et al., 2014; Table 3), (C) microbial co-abundance groups (Candela et al., 2014; Table 2 bottom), and (D) best aligned strains to metagenomic linkage groups in fecal samples (Feng et al., 2015; Table 4). The mean amino acid composition of proteins in the Homo sapiens genome (Hsa) is also shown.

selected species with positive enrichment in cancer. Although every uniquely named strain given by Feng et al. (2015) was used in the comparisons below ( $n=44$; see Fig. 3D below), for clarity only the up-enriched species that appear in the calculated stability diagram (see Fig. 4D below) are listed in Table 4 and labeled in Fig. 3D. File microbes. CSv in Dataset S1 contains the complete list of Bioproject IDs and calculated $Z_{\mathrm{C}}$ and $\bar{n}_{\mathrm{H}_{2} \mathrm{O}}$ for all the microbial species considered here.

For each of the microbial species listed in Tables $2-4$, a mean protein composition 
was calculated by combining amino acid sequences of all proteins downloaded from the NCBI genome page associated with the Bioproject IDs shown in the Tables (see file microbial.aa. CSV in Dataset S1). This method does not account for actual protein abundances in organisms, and excludes any post-translational modifications. Calculation of the mean amino acid composition of proteins in this way is not an exact representation of the cellular protein composition, but provides a starting point for identifying environmental signals in protein composition. Mean amino acid compositions or amino acid frequencies deduced from microbial genomes, calculated without weighting for actual protein abundance, have been used in many studies making evolutionary and/or environmental comparisons (e.g. Tekaia and Yeramian, 2006; Zeldovich et al., 2007; Brbić et al., 2015). In the future, more refined calculations may be possible by using genome-wide estimates of protein expression levels based on codon usage patterns (e.g. Moura et al., 2013; Brbić et al., 2015).

The water demand per residue $\left(\bar{n}_{\mathrm{H}_{2} \mathrm{O}}\right)$ vs. oxidation state of carbon $\left(Z_{\mathrm{C}}\right)$ in the mean amino acid compositions of proteins from all of the microbial species considered here are plotted in Fig. 1B and D, and for individual datasets in Fig. 3. The groups of proteins in the microbes enriched in cancer patients have somewhat lower $Z_{C}$ than those enriched in healthy donors in the same study. The dataset from Feng et al. (2015) (Fig. 3D) shows a more complex distribution, where the microbes with a relative enrichment in healthy individuals form two clusters at high and low $Z_{C}$. The Fusobacterium species identified in the studies of Zeller et al. (2014), Candela et al. (2014) and Feng et al. (2015) have the lowest $Z_{C}$ of any microbial species considered here. The mean human protein composition is also plotted in Fig. 3, revealing a higher $Z_{C}$ than any of the mean microbial proteins except for Actinomyces viscosus and Bifidobacterium animalis, identified in the study of Feng et al. (2015) (Fig. 3D). The tendency for microbial organisms to be composed of more reduced biomolecules than the host may reflect the relatively reducing conditions in the gut.

\subsection{Thermodynamic descriptions: background}

Going beyond compositional comparisons, thermodynamic descriptions can account for stoichiometric and energetic constraints and provide a richer interpretation of proteomic data in the context of tumor microenvironments.

By combining both stoichiometric and energetic variables, a thermodynamic description of proteomic data reveals possible biochemical constraints that may arise within cells and in tumor microenvironments. To give an example of how relative stabilities of up- and down-expressed proteins in a proteomic dataset can be calculated as a function of chemical potentials, consider Reaction R3 above written for the formation of one mole of MUC1. In order to compare proteins of different lengths, the formula of the protein is written per residue. The corresponding reaction is then

$$
\begin{aligned}
& 0.006 \mathrm{C}_{3} \mathrm{H}_{7} \mathrm{NO}_{2} \mathrm{~S}+ 0.427 \mathrm{C}_{5} \mathrm{H}_{9} \mathrm{NO}_{4}+0.411 \mathrm{C}_{5} \mathrm{H}_{10} \mathrm{~N}_{2} \mathrm{O}_{3} \rightarrow \\
& \mathrm{C}_{4.203} \mathrm{H}_{8.557} \mathrm{~N}_{1.253} \mathrm{O}_{2.403} \mathrm{~S}_{0.006}+0.714 \mathrm{H}_{2} \mathrm{O}+0.416 \mathrm{O}_{2}
\end{aligned}
$$


et al., 2009) of Reaction R4 is

$$
A=2.303 R T \log (K / Q)
$$

where 2.303 is shorthand for the natural logarithm of $10, R$ is the gas constant, $T$ is temperature, log represents the common (decimal) logarithm, and the activity quotient $Q$ is given by

$$
\begin{aligned}
\log Q= & \log a_{\mathrm{C}_{4.203} \mathrm{H}_{8.557} \mathrm{~N}_{1.253} \mathrm{O}_{2.403} \mathrm{~S}_{0.006}+0.714 \log a_{\mathrm{H}_{2} \mathrm{O}}+0.416 \log f_{\mathrm{O}_{2}}} \\
& -0.006 \log a_{\mathrm{C}_{3} \mathrm{H}_{7} \mathrm{NO}_{2} \mathrm{~S}}-0.427 \log a_{\mathrm{C}_{5} \mathrm{H}_{9} \mathrm{NO}_{4}}-0.411 \log a_{\mathrm{C}_{5} \mathrm{H}_{10} \mathrm{~N}_{2} \mathrm{O}_{3}}
\end{aligned}
$$

The equilibrium constant is given by $\log K=-2.303 R T \Delta G_{r}^{\circ}$, where $\Delta G_{r}^{\circ}$ is the standard Gibbs energy of the reaction. As noted above, the standard Gibbs energies of species used to calculate $\Delta G_{r}^{\circ}$ at $T=37^{\circ} \mathrm{C}$ are generated using amino acid group additivity for the proteins and published values for standard thermodynamic properties of the basis species in the reaction.

To compare the potential for formation of metastable molecules, the per-residue formulas of the proteins are assigned equal activities (1). Then, Eqs. (4)-(5) show that the affinity, and hence relative potential for formation of different proteins, is a function of not only their amino acid composition (which determines the chemical formulas and standard Gibbs energies of the proteins used here), but also system parameters including temperature and the chemical potentials of the components. In this study, the chemical activities of the amino acid basis species are provisionally set to constant values $\left(10^{-4}\right)$, while $\log f_{\mathrm{O}_{2}}$ and $\log a_{\mathrm{H}_{2} \mathrm{O}}$ are considered to be adjustable parameters that are used as exploratory variables. The ranges of these variables shown on the diagrams are selected in order to encompass the stability boundaries between groups of proteins differentially enriched in cancer and normal samples.

There are combinations of chemical activities of basis species in Eq. (5) where the per-residue formation reactions of two proteins have an equal affinity, indicating equal chemical stability of the proteins. Other combinations of chemical activities of basis species give the result that one protein-residue formula has a higher affinity than the other(s), indicating greater stability of this protein. This concept provides an approach for constructing stability diagrams, which may be called the "maximum affinity method", that can be used to reproduce published equilibrium and metastable equilibrium diagrams for many inorganic and organic systems as shown by examples in the CHNOSZ package (Dick, 2008) and is used below for microbial proteins. Because of the greater numbers of individual proteins in human proteomic datasets, a new method based on the difference in weighted sums of ranks of affinities is used here to compare the relative stabilities of groups of up- and down-expressed proteins in cancer.

\subsection{Relative stability fields for microbial proteins}

Stability diagrams are shown in Fig. 4A-D for the four sets of microbial proteins described above. The first diagram, representing significantly changed genera detected in fecal 16S rRNA (Wang et al., 2012; first part of Table 2), shows maximal stability fields for proteins from 5 species relatively enriched in healthy patients, and 3 species 

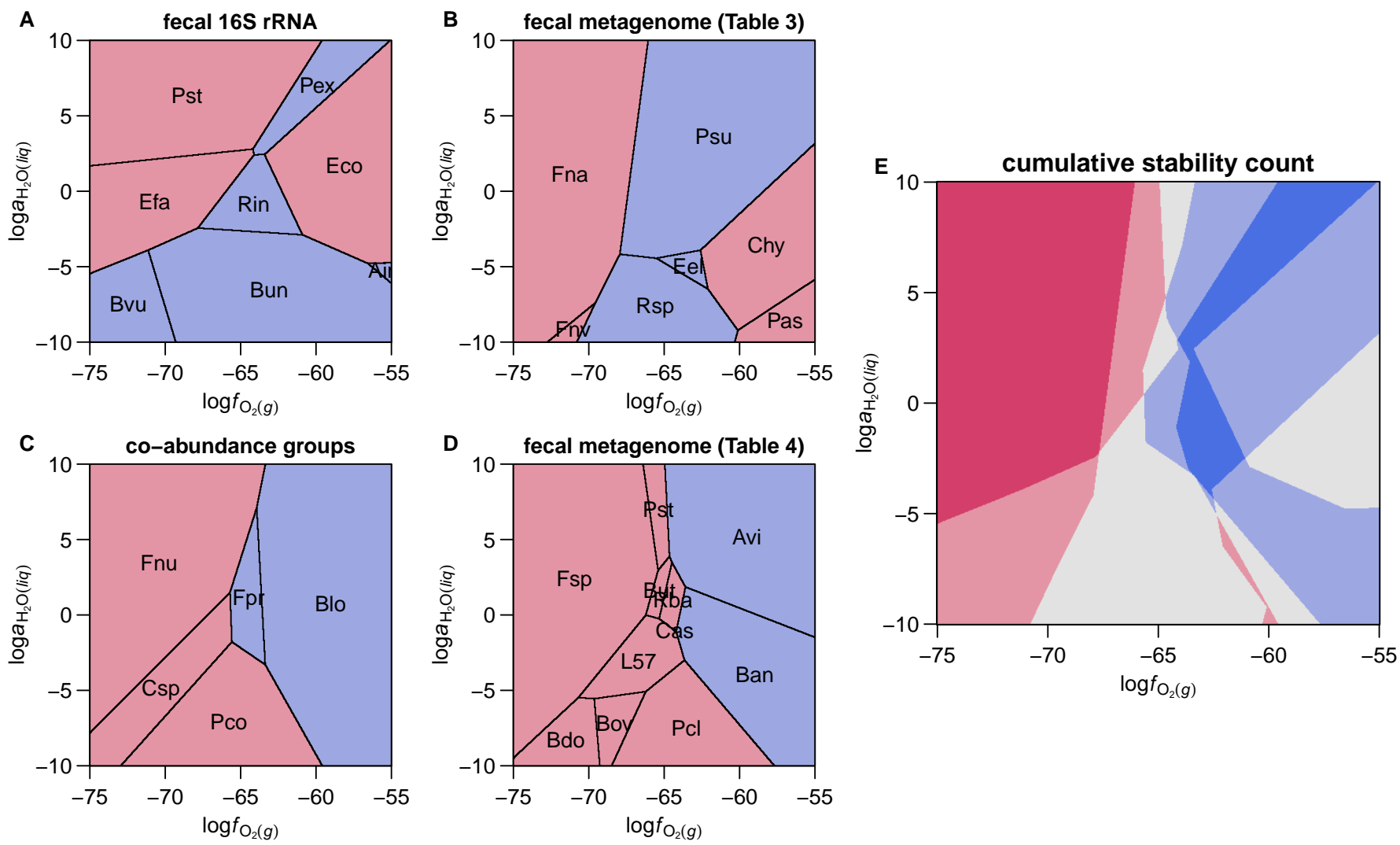

Figure 4. Maximal relative stability diagrams for mean microbial protein compositions. Each stability field in these diagrams shows the ranges of oxygen fugacity and water activity (in log units: $\log f_{\mathrm{O}_{2}}$ and $\log a_{\mathrm{H}_{2} \mathrm{O}}$ ) where the mean protein composition from the labeled microbial species has a higher per-residue affinity (lower Gibbs energy) of formation than the others. Blue and red shading designate microbes relatively enriched in samples from healthy donors and cancer patients, respectively. Plot (E) is a composite figure in which the intensity of shading corresponds to the number of overlapping healthy- or cancer-enriched microbes in the preceding diagrams.

enriched in CRC patients. The other 4 proteins in the system are less stable than the others within the range of $\log f_{\mathrm{O}_{2}}$ and $\log a_{\mathrm{H}_{2} \mathrm{O}}$ shown and do not appear on the diagram. The relative positions of the stability fields in Fig. $4 \mathrm{~A}$ are roughly aligned with the values of $Z_{\mathrm{C}}$ and $\bar{n}_{\mathrm{H}_{2} \mathrm{O}}$ of the proteins; note for example the high- $\log f_{\mathrm{O}_{2}}$ positions of the fields for the relatively high- $Z_{\mathrm{C}}$ Escherichia coli and Alistipes indistinctus, and the high- $\log a_{\mathrm{H}_{2} \mathrm{O}}$ position of the field for the high- $\bar{n}_{\mathrm{H}_{2} \mathrm{O}}$ Peptostreptococcus stomatis. Except for E. coli, the proteins from the species enriched in CRC occupy the lower $\log f_{\mathrm{O}_{2}}$ (reducing) and higher $\log a_{\mathrm{H}_{2} \mathrm{O}}$ zones of this diagram.

In thermodynamic calculations for proteins from bacteria detected in fecal metagenomes (Zeller et al., 2014; Table 3), the mean protein compositions of 3 of 6 healthy-enriched microbes and 4 of 7 cancer-enriched microbes exhibit maximal relative stability fields (Fig. 4B). Here, the cancer-associated proteins occupy the more reducing (Fusobacterium nucleatum subsp. vincentii and subsp. animalis) or more oxidizing (Clostridium hylemonae, Porphyromonas asaccharolytica) regions, while the proteins from bacteria more abundant in healthy individuals are relatively stable at 
moderate oxidation-reduction conditions.

For the bacterial species representing microbial co-abundance groups (Candela et al., 2014; second part of Table 2), all of the 5 mean protein compositions are present on the diagram (Fig. 4C). Here, the proteins from cancer-enriched bacteria are more stable at reducing conditions and those from healthy-enriched microbes are stabilized by oxidizing conditions.

A stability diagram for proteins of bacteria identified in a second metagenomic study (Feng et al., 2015) shows a similar result (Fig. 3D) for the 11 mean protein compositions with highest stability at some point the diagram. These patterns in relative stability again reflect the differences in $Z_{\mathrm{C}}$ of the proteins, although in this case, a greater proportion of proteins (33 out of the 44 included in the calculations) are not found to have maximal stability fields. The resulting stability diagram is therefore a more limited portrayal of the available data.

Fig. 4E is a composite representation of the calculations, in which higher cumulative counts of maximal stability of proteins from bacteria enriched in normal and cancer samples in the four studies are represented by deeper blue and red shading, respectively. According to this diagram, the chemical conditions predicted to be most favorable for the formation of proteins in many bacteria enriched in CRC are characterized by low $\log f_{\mathrm{O}_{2}}$. Proteins from bacteria that are abundant in healthy patients tend to be stabilized by moderate values of $\log f_{\mathrm{O}_{2}}$. Despite the differences in experimental design and microbial identification between studies, the thermodynamic calculations reveal a shared pattern of relative stabilities among the four datasets considered here.

\subsection{Relative stability fields for human proteins}

Diagrams like those shown above that portray the maximally stable protein compositions are inadequate for analysis of larger datasets such as those generated in proteomic studies. It is apparent in Fig. 5 that only three different proteins up-expressed in cancer, from the 106 proteins in the KWA 14 dataset (chromatin-binding proteins in carcinoma / adenoma), are maximally stable across a range of $\log f_{\mathrm{O}_{2}}$. However, visual inspection reveals a differential sensitivity to oxygen fugacity in the whole dataset, with lower $\log f_{\mathrm{O}_{2}}$ providing relatively higher potential for the formation of many of the up-expressed proteins in carcinoma samples. How can these responses be quantified in order to explore the data in multiple dimensions, including both $\log a_{\mathrm{H}_{2} \mathrm{O}}$ and $\log f_{\mathrm{O}_{2}}$ ?

In Fig. 5B, the difference in mean values of chemical affinity per residue of carcinoma and adenoma-associated proteins appears as a straight line as a function of $\log f_{\mathrm{O}_{2}}$. This linear behavior would translate to evenly spaced isostability (taken as constant mean affinity difference) contours on a $\log f_{\mathrm{O}_{2}}-\log a_{\mathrm{H}_{2} \mathrm{O}}$ diagram. The weighted rank difference of affinities (see Methods), shown by the curved line Fig. 5B, is a summary function that is more informative of changing chemical conditions. The variable slope is greatest near the zone of convergence for affinities of individual proteins (Fig. 5A), corresponding to the transition zone between groups of proteins. The resulting two-dimensional stability diagrams shown below have curved and diversely spaced isostability (taken as constant weighted rank difference of affinity) contours.

The diagrams in Fig. 6 portray weighted rank differences of chemical affinities of formation between groups of up- and down-expressed proteins reported for proteomic experiments. These combined depictions of stoichiometric and energetic differences 

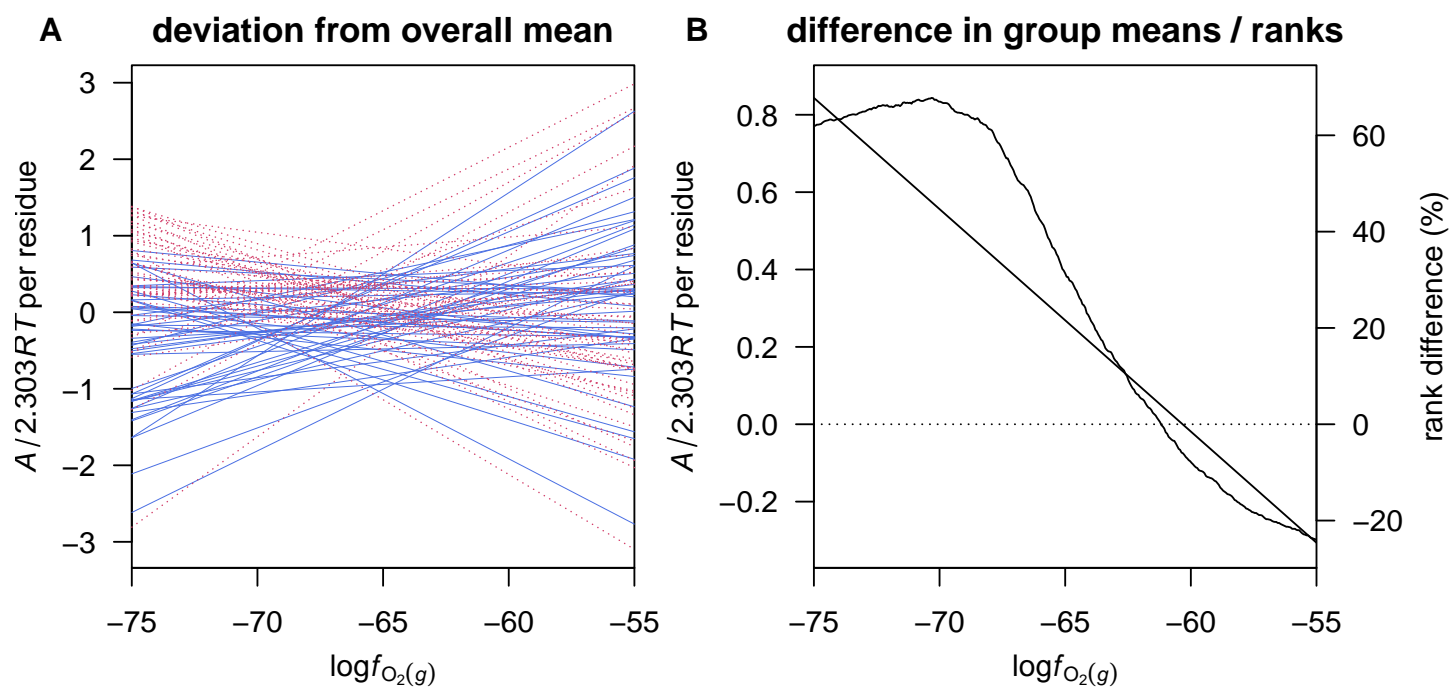

Figure 5. Calculated chemical affinities per residue of proteins in the KWA+14 dataset. Values for individual proteins as a function of $\log f_{\mathrm{O}_{2}}$ at $\log a_{\mathrm{H}_{2} \mathrm{O}}=0$ are shown in plot (A) as deviations from the mean value for all proteins. Down- and up-expressed proteins in carcinoma compared to adenoma are indicated by solid blue and dashed red lines, respectively. Plot (B) shows the difference in mean value between down- and up-expressed proteins (straight line and left-hand $y$-axis) and the weighted difference in sums of ranks of affinities as a percentage of maximum possible rank-sum difference (Eq. 3; curved line and right-side $y$-axis). Positive values of affinity or rank-sum difference in plot (B) correspond to relatively greater stability of the up-expressed proteins.

constitute a theoretical prediction of the relative chemical (not conformational) stabilities of the proteins.

The slopes of the equal-stability lines and the positions of the stability fields reflect the magnitude and sign of differences in $Z_{\mathrm{C}}$ and $\bar{n}_{\mathrm{H}_{2} \mathrm{O}}$. Figs. $6 \mathrm{~A}-\mathrm{C}$ show results for datasets that are dominated by differences in $\bar{n}_{\mathrm{H}_{2} \mathrm{O}}$; the nearly horizontal lines show that relative stabilities are accordingly more sensitive to $\log a_{\mathrm{H}_{2} \mathrm{O}}$ than $\log f_{\mathrm{O}_{2}}$. The second row depicts relative stabilities in the three datasets from Mikula et al. (2011), which have large changes in, sequentially, $\bar{n}_{\mathrm{H}_{2} \mathrm{O}}, Z_{\mathrm{C}}$, then both of these (Table 1). Accordingly, the equal-stability lines for these datasets are closer to horizontal, closer to vertical, or have a more diagonal trend (Fig. 6D-F).

The last row shows results for datasets that are characterized by large changes in $Z_{C}$; the relative stabilities depend strongly on $\log f_{\mathrm{O}_{2}}$. According to Fig. 6G, higher oxygen fugacity increases the relative potential for the formation of proteins up-expressed in cancer (dataset of Jankova et al., 2011). However, in a dataset for up- and down-expressed chromatin-binding proteins in carcinoma (Knol et al., 2014), lower $\log f_{\mathrm{O}_{2}}$ is predicted to promote formation of the proteins up-expressed in carcinoma. This is the opposite trend to that found for most of the other datasets with significant differences in $Z_{\mathrm{C}}$. These opposing trends might be attributed to different biochemical constraints acting at the subcellular and cellular or tissue levels during carcinogenesis. 

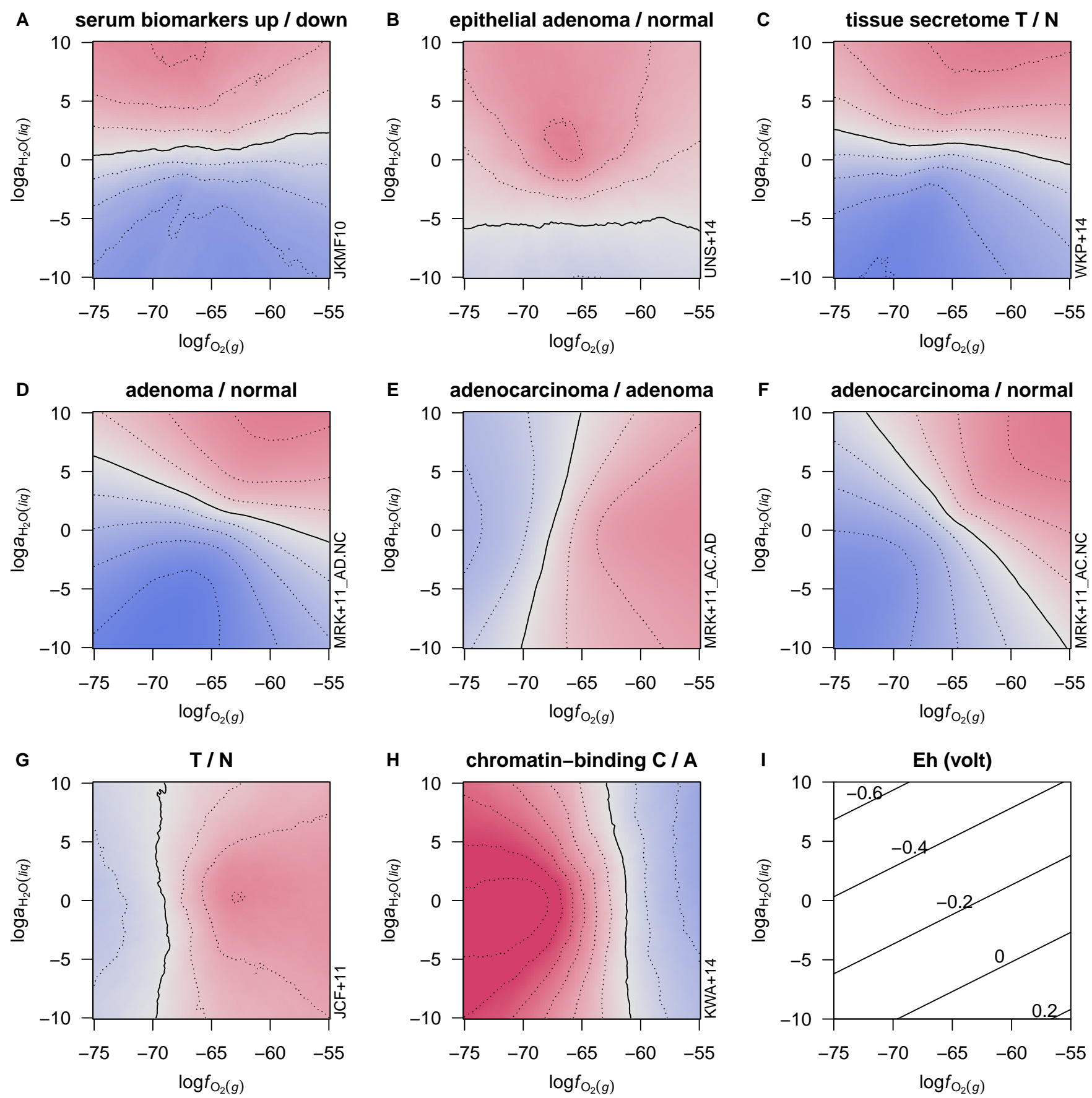

Figure 6. Weighted rank-sum comparisons of chemical affinities of formation of human proteins as a function of $\log f_{\mathrm{O}_{2}}$ and $\log a_{\mathrm{H}_{2} \mathrm{O}}$. The solid lines indicate equal ranking of proteins in the "normal" and "cancer" groups (Table 1), and dotted contours are drawn at 10\% increments of the maximum possible rank-sum difference. Blue and red areas correspond to higher ranking of cancer- and normal-enriched proteins, respectively, with the intensity of the shading increasing up to $50 \%$ the maximum possible rank-sum difference. (For readers without a color copy: the stability fields for proteins up-expressed in cancer lie above (A-D), to the right of (E-G), or to the left of $(\mathrm{H})$ the stability fields for proteins with higher expression in normal tissue.) Panel (I) shows calculated values of Eh over the same ranges of $\log f_{\mathrm{O}_{2}}$ and $\log a_{\mathrm{H}_{2} \mathrm{O}}$ (cf. Reaction R4). 
The full set of diagrams for all datasets listed in Table 1 is provided in Figure S1. It is notable that for the datasets where the relative stabilities are strongly a function of $\log a_{\mathrm{H}_{2} \mathrm{O}}$ (sub-horizontal lines), the equal-stability lines are within a few $\log$ units of 0 (unit activity). Equal-stability lines that are diagonal often cross unit activity of $\mathrm{H}_{2} \mathrm{O}$ at a moderate value of $\log f_{\mathrm{O}_{2}}$, near -65 to -60 (see Figure S1). This could be indicative of a tendency for these proteomic transformations to be partially buffered by other redox reactions in the cell, and/or by liquid-like $\mathrm{H}_{2} \mathrm{O}$ with close to unit activity.

Effective values of oxidation-reduction potential (Eh) can be calculated by considering the water dissociation reaction, i.e.

$$
\mathrm{H}_{2} \mathrm{O} \rightleftharpoons \frac{1}{2} \mathrm{O}_{2}+2 \mathrm{H}^{+}+2 e^{-}
$$

If one assumes that $\log a_{\mathrm{H}_{2} \mathrm{O}}=0$ (unit water activity, as in an infinitely dilute solution), this reaction can be used to interconvert $\log f_{\mathrm{O}_{2}}, \mathrm{pH}$ and pe (or, in conjunction with the Nernst equation, Eh) (e.g. Garrels and Christ, 1965, p. 176; Anderson, 2005, p. 363). However, in the approach utilized here for assessing the relative stabilities of proteins in a subcellular context, no such assumptions are made on the operational value of $\log a_{\mathrm{H}_{2} \mathrm{O}}$. Instead, it is used as an indicator of the internal state of the system, and is not necessarily buffered by an aqueous solution. Consequently, the effective Eh is considered to be a function of variable $\log f_{\mathrm{O}_{2}}$ and $\log a_{\mathrm{H}_{2} \mathrm{O}}$, as shown in Fig. $6 \mathrm{I}$ for $\mathrm{pH}$ $=7.4$ and $T=37^{\circ} \mathrm{C}$. This comparison gives some perspective on operationally reasonable ranges of $\log f_{\mathrm{O}_{2}}$ and $\log a_{\mathrm{H}_{2} \mathrm{O}}$.

The subcellular reduction potential monitored by the reduced glutathione (GSH) / oxidized glutathione disulfide (GSSG) couple ranges from ca. $-260 \mathrm{mV}$ for proliferating cells to ca. $-170 \mathrm{mV}$ for apoptotic cells (Schafer and Buettner, 2001), lying toward the middle part of the range of conditions shown in Fig. 6. A physiologically plausible Eh value of $-0.2 \mathrm{~V}$, corresponding to $\log f_{\mathrm{O}_{2}}=-62.8$ at unit activity of $\mathrm{H}_{2} \mathrm{O}$, is close to the stability transitions for many of the datasets considered here (see also Figure S1).

\subsection{Comparison with inorganic basis species}

Figures made using Basis I (inorganic basis species, e.g. Reaction R1) are provided in the Supplemental Information (human proteins: Figure S2; microbial proteins: Figure S3). The stability boundaries in $\log a_{\mathrm{H}_{2} \mathrm{O}}-\log f_{\mathrm{O}_{2}}$ diagrams constructed using Basis I cluster around a common, positive slope, in contrast with the greater diversity of slopes appearing on the corresponding diagrams constructed using Basis II (Figure S1).

As noted above, all mathematically possible choices for the basis species of a system are thermodynamically valid, but it appears that Basis II affords a greater convenience for interpretation. That is, compared to to Basis I, Basis II yields a greater degree of separation of the effects of changing chemical potentials of $\mathrm{H}_{2} \mathrm{O}$ and $\mathrm{O}_{2}$ under the assumption that the activities of the remaining basis species (inorganic species in Basis I, or amino acids in Basis II) are held constant. However, it is also notable that two of the diagrams constructed using Basis I (Figure S2), unlike the others, have nearly horizontal equal-stability lines, showing that increasing activity of $\mathrm{H}_{2} \mathrm{O}$ at constant activity of $\mathrm{CO}_{2}, \mathrm{NH}_{3}, \mathrm{H}_{2} \mathrm{~S}$ and fugacity of $\mathrm{O}_{2}$ gives an energetic advantage to the formation of potential up-expressed serum biomarkers (dataset JKMF 10; Jimenez et al., 2010) and proteins up-expressed in an "epithelial cell signature" for adenoma (dataset 
UNS+14; Uzozie et al., 2014). These datasets are also found to be among those having significantly differential water demand using Basis II (Table 1; Figure S1). Based on the similar results for these datasets using different choices of chemical components, it can be suggested that the compositions of the differentially expressed proteins in these datasets are especially indicative of changes in hydration potential.

\section{DISCUSSION}

Among 35 proteomic datasets considered here (Table 1), many have significantly higher values of average oxidation state of carbon $\left(Z_{C}\right)$ in proteins up-expressed in adenoma or carcinoma compared to normal tissue. While a decrease in oxidation state might be expected if the differential expression of proteins was to some extent an adaptation to hypoxic conditions in tumors, the observed increase is more consistent with potentially oxidizing subcellular conditions that may accompany mitochondrial generation of ROS.

Available data for the adenoma to carcinoma transition are less conclusive: different datasets have relatively higher (Mikula et al., 2011) or lower (Wiśniewski et al., 2015) $Z_{\mathrm{C}}$ of up-expressed proteins in carcinoma. A trend toward more reduced proteins in carcinoma compared to adenoma is also apparent in datasets for nuclear matrix fractions in chromosomal instability (CIN-type) CRC (Albrethsen et al., 2010) and for chromatin-binding fractions (Knol et al., 2014). It is possible that particular subtypes of cancer and/or subfractions of cells have patterns of protein expression during carcinogenesis that are chemically distinct from trends observed at the tissue level.

Some proteomic datasets are also available for stromal cells associated with tumor tissues. Data from one study (Mu et al., 2013) are consistent with the generally observed higher $Z_{\mathrm{C}}$ of protein in in tumors, but data from a pair of recent studies that analyzed cancer and stromal cells from the same set of tissues (Li et al., 2016; Peng et al., 2016) show that the proteins up-expressed in stromal cells, but not tumor cells, of adenoma are reduced compared to normal cells. Also, proteins up-expressed in tumor cells, but not stromal cells from carcinoma in situ, have a relatively oxidized composition (Table 1). If an opposing trend in $Z_{\mathrm{C}}$ between stromal and epithelial cells is indeed established, it might be evidence for a proteome-level manifestation of metabolic coupling (Martinez-Outschoorn et al., 2014) between tissue compartments in cancer. The "lactate shuttle" between metabolically coupled cells can be characterized in part by the difference between oxidation states of carbon in lactate $\left(Z_{C}=0\right)$ and pyruvate $\left(Z_{C}=0.667\right)$ (Brooks, 2009). More work is needed to understand how the fluxes of anabolic precursors and catabolic products between tissue compartments might contribute to the differential oxidation states of carbon in proteins observed in cancer.

The datasets available for comparison of mean protein compositions of bacteria enriched in healthy subjects and cancer patients are characterized by lower $Z_{C}$ in proteins of bacteria with higher abundance in cancer patients (Fig. 3), and consequently stabilization of these proteins by lower oxygen fugacity $\left(\log f_{\mathrm{O}_{2}} ;\right.$ Fig. 4). This trend could be viewed as an adaptation of microbial communities to minimize the energetic costs of biomass synthesis in more reducing conditions. The opposite trends in $Z_{C}$ for the human and bacterial proteins also raises the possibility that their mutual proteomic makeup is partially the result of a redox balance, or coupling.

Another major outcome of the compositional comparisons of human proteomes is 
the increase in water demand per residue $\left(\bar{n}_{\mathrm{H}_{2} \mathrm{O}}\right)$ apparent in some datasets for CRC tissues and in a list of candidate biomarkers summarized in a literature review (Jimenez et al., 2010) (Table 1). Higher hydration levels in breast cancer tissues have been observed spectroscopically (Abramczyk et al., 2014), and it has been proposed that increased hydration plays a role in reversion to an embryological mode of growth (McIntyre, 2006). The thermodynamic calculations used to generate Fig. 6 support the possibility that higher water activity increases the potential for formation of the proteins up-expressed in cancer relative to normal tissue.

Although the ranges of $\log a_{\mathrm{H}_{2} \mathrm{O}}$ and $\log f_{\mathrm{O}_{2}}$ derived from the model indicate to some extent the hydration and oxidation states of the system, they can not be interpreted directly in terms of measurable concentrations of water and oxygen. There are astronomical differences between theoretical values of oxygen fugacity in thermodynamic models and actual concentrations or partial pressures of oxygen (e.g. Anderson, 2005, p. 364-365). Partial pressures of oxygen in human arterial blood are around $90-100 \mathrm{mmHg}$, and approximate threshold values for physiological hypoxia include $10 \mathrm{mmHg}$ for energy metabolism, $0.5 \mathrm{mmHg}$ for mitochondrial oxidative phosphorylation, and $0.02 \mathrm{mmHg}$ for full oxidation of cytochromes (Höckel and Vaupel, 2001). Assuming ideal mixing, the equivalent range of oxygen fugacities indicated by these measurements is $\log f_{\mathrm{O}_{2}}=-4.57$ to -0.88 , higher by far than the values that delimit the relative stabilities of cancer- and normal-enriched proteins computed here.

Likewise, the ranges of $\log a_{\mathrm{H}_{2} \mathrm{O}}$ calculated here deviate tremendously from laboratory-based determination of water activity or hydration levels. Water activity in saturated protein solutions is not lower than 0.5 (Knezic et al., 2004), and recent experiments and extrapolations predict a range of ca. 0.600 to 0.650 for growth of various xerophilic and halophilic eukaryotes and prokaryotes (Stevenson et al., 2015). In general, cytoplasmic water activity is probably not greatly different from aqueous growth media, at 0.95 to 1 (Cayley et al., 2000). The theoretically computed transitions in relative stabilities between proteins from cancer and healthy tissues occur at much lower values of $a_{\mathrm{H}_{2} \mathrm{O}}$ (ca. $10^{-6} ; \mathrm{Fig}$. 6B) or at values approaching 1 , depending on the oxygen fugacity (Fig. 6; Figure S1).

Despite the difficulties in a quantitative interpretation, theoretical predictions of stabilization of cancer-related proteins by an increase in $\log f_{\mathrm{O}_{2}}$ (e.g. Fig. 6D-G) can be interpreted qualitatively as corresponding with an increase in effective redox potential if $\log a_{\mathrm{H}_{2} \mathrm{O}}$ is held constant (Fig. 6I). Alternatively, proteins up-expressed in cancer tissues in each of the datasets shown in Fig. 6A-G can be relatively stabilized along a trajectory of increasing both $\log f_{\mathrm{O}_{2}}$ and $\log a_{\mathrm{H}_{2} \mathrm{O}}$ at constant effective redox potential near $-0.2 \mathrm{~V}$ (Fig. 6I). Under this interpretation, local increases in both oxidation and hydration state are likely contributors to the proteomic transformations in colorectal cancer.

\section{CONCLUSION}

An integrated picture of proteomic remodeling in cancer may benefit from accounting for the stoichiometric and energetic requirements of protein formation. This study has identified a strong shift toward higher average oxidation state of carbon in proteins that are more highly expressed in colorectal cancer. This pattern is identified across multiple data sets, increasing confidence in its systematic nature. In some other data sets, a 
systematic change can be identified indicating greater water demand for formation of human proteins in cancer compared to normal tissue.

The proteomic data can be theoretically linked to microenvironmental conditions using thermodynamic models, which give estimates of the oxidation- and hydration-potential limits for relative stability of groups of proteins. These calculations outline a path connecting the dynamic compositions of proteomes to biochemical measurements such as Eh. This approach can be used in conjunction with other datasets to characterize chemical changes in proteomes in different types of cancer and in the progression to metastasis.

\section{ACKNOWLEDGEMENTS}

Thanks to Greg Anderson for a helpful discussion about chemical components and Apar Prasad for giving many useful comments on the manuscript.

\section{REFERENCES}

Abramczyk, H., Brozek-Pluska, B., Krzesniak, M., Kopec, M., and Morawiec-Sztandera, A. (2014). The cellular environment of cancerous human tissue. Interfacial and dangling water as a "hydration fingerprint". Spectrochimica Acta, Part A: Molecular and Biomolecular Spectroscopy, 129(0):609-623. DOI 10.1016/j.saa.2014.03.103.

Albarède, F. (2011). Oxygen fugacity. In Gargaud, M., Amils, R., Quintanilla, J. C., Cleaves, H. J. J., Irvine, W. M., Pinti, D. L., and Viso, M., editors, Encyclopedia of Astrobiology, pages 1196-1196. Springer, Berlin, Heidelberg. DOI 10.1007/978-3-642-11274-4_4021.

Alberty, R. A. (2004). Equilibrium concentrations for pyruvate dehydrogenase and the citric acid cycle at specified concentrations of certain coenzymes. Biophysical Chemistry, 109(1):73-84. DOI 10.1016/j.bpc.2003.10.019.

Albrethsen, J., Knol, J. C., Piersma, S. R., Pham, T. V., de Wit, M., Mongera, S., Carvalho, B., Verheul, H. M. W., Fijneman, R. J. A., Meijer, G. A., and Jimenez, C. R. (2010). Subnuclear proteomics in colorectal cancer: Identification of proteins enriched in the nuclear matrix fraction and regulation in adenoma to carcinoma progression. Molecular \& Cellular Proteomics, 9(5):988-1005. DOI 10.1074/mcp.M900546-MCP200.

Amend, J. P., LaRowe, D. E., McCollom, T. M., and Shock, E. L. (2013). The energetics of organic synthesis inside and outside the cell. Philosophical Transactions of the Royal Society, B: Biological Sciences, 368(1622):20120255. DOI 10.1098/rstb.2012.0255.

Amend, J. P. and Shock, E. L. (1998). Energetics of amino acid synthesis in hydrothermal ecosystems. Science, 281(5383):1659-1662. DOI 10.1126/science.281.5383.1659. 
Anderson, G. M. (2005). Thermodynamics of Natural Systems. Cambridge University Press, Cambridge, 2nd edition. URL http://www.worldcat.org/oclc/474880901.

Arndt, S., Jørgensen, B. B., LaRowe, D. E., Middelburg, J. J., Pancost, R. D., and Regnier, P. (2013). Quantifying the degradation of organic matter in marine sediments: A review and synthesis. Earth-Science Reviews, 123(0):53-86. DOI 10.1016/j.earscirev.2013.02.008.

Besson, D., Pavageau, A.-H., Valo, I., Bourreau, A., Bélanger, A., Eymerit-Morin, C., Moulière, A., Chassevent, A., Boisdron-Celle, M., Morel, A., Solassol, J., Campone, M., Gamelin, E., Barré, B., Coqueret, O., and Guette, C. (2011). A quantitative proteomic approach of the different stages of colorectal cancer establishes OLFM4 as a new nonmetastatic tumor marker. Molecular \& Cellular Proteomics, 10(12):M111.009712. DOI 10.1074/mcp.M111.009712.

Bethke, C. M. (2008). Geochemical and Biogeochemical Reaction Modeling. Cambridge University Press, 2nd edition. URL http://www.worldcat.org/oclc/619593307.

Biarc, J., Nguyen, I. S., Pini, A., Gossé, F., Richert, S., Thiersé, D., Van Dorsselaer, A., Leize-Wagner, E., Raul, F., Klein, J.-P., and Schöller-Guinard, M. (2004). Carcinogenic properties of proteins with pro-inflammatory activity from Streptococcus infantarius (formerly S.bovis). Carcinogenesis, 25(8):1477-1484. DOI 10.1093/carcin/bgh091.

Bohutskyi, P., Chow, S., Ketter, B., Betenbaugh, M. J., and Bouwer, E. J. (2015). Prospects for methane production and nutrient recycling from lipid extracted residues and whole Nannochloropsis salina using anaerobic digestion. Applied Energy, 154:718-731. DOI 10.1016/j.apenergy.2015.05.069.

Borak, B., Ort, D. R., and Burbaum, J. J. (2013). Energy and carbon accounting to compare bioenergy crops. Current Opinion in Biotechnology, 24(3):369-375. DOI 10.1016/j.copbio.2013.02.018.

Brbić, M., Warnecke, T., Kriško, A., and Supek, F. (2015). Global shifts in genome and proteome composition are very tightly coupled. Genome Biology and Evolution, 7(6):1519-1532. DOI 10.1093/gbe/evv088.

Brooks, G. A. (2009). Cell-cell and intracellular lactate shuttles. Journal of Physiology, 587(23):5591-5600. DOI 10.1113/jphysiol.2009.178350.

Callen, H. B. (1985). Thermodynamics and an Introduction to Thermostatistics. John Wiley \& Sons, 2nd edition. URL http://www.worldcat.org/oclc/11916089.

Candela, M., Turroni, S., Biagi, E., Carbonero, F., Rampelli, S., Fiorentini, C., and Brigidi, P. (2014). Inflammation and colorectal cancer, when microbiota-host mutualism breaks. World Journal of Gastroenterology, 20(4):908-922. DOI 10.3748/wjg.v20.i4.908. 
Castellarin, M., Warren, R. L., Freeman, J. D., Dreolini, L., Krzywinski, M., Strauss, J., Barnes, R., Watson, P., Allen-Vercoe, E., Moore, R. A., and Holt, R. A. (2012). Fusobacterium nucleatum infection is prevalent in human colorectal carcinoma. Genome Research, 22(2):299-306. DOI 10.1101/gr.126516.111.

Cayley, D. S., Guttman, H. J., and Record, Jr., M. T. (2000). Biophysical characterization of changes in amounts and activity of Escherichia coli cell and compartment water and turgor pressure in response to osmotic stress. Biophysical Journal, 78(4):1748-1764. DOI 10.1016/S0006-3495(00)76726-9.

Chen, W., Liu, F., Ling, Z., Tong, X., and Xiang, C. (2012). Human intestinal lumen and mucosa-associated microbiota in patients with colorectal cancer. PLOS ONE, 7(6):e39743. DOI 10.1371/journal.pone.0039743.

Damer, B. and Deamer, D. (2015). Coupled phases and combinatorial selection in fluctuating hydrothermal pools: A scenario to guide experimental approaches to the origin of cellular life. Life, 5(1):872-887. DOI 10.3390/life5010872.

Davies, P. C. W., Demetrius, L., and Tuszynski, J. A. (2011). Cancer as a dynamical phase transition. Theoretical Biology and Medical Modelling, 8:30. DOI 10.1186/1742-4682-8-30.

de Wit, M., Fijneman, R. J. A., Verheul, H. M. W., Meijer, G. A., and Jimenez, C. R. (2013). Proteomics in colorectal cancer translational research: Biomarker discovery for clinical applications. Clinical Biochemistry, 46(6):466-479. DOI 10.1016/j.clinbiochem.2012.10.039.

de Wit, M., Kant, H., Piersma, S. R., Pham, T. V., Mongera, S., van Berkel, M. P. A., Boven, E., Pontén, F., Meijer, G. A., Jimenez, C. R., and Fijneman, R. J. A. (2014). Colorectal cancer candidate biomarkers identified by tissue secretome proteome profiling. Journal of Proteomics, 99:26-39. DOI 10.1016/j.jprot.2014.01.001.

DeBerardinis, R. J. and Cheng, T. (2010). Q's next: The diverse functions of glutamine in metabolism, cell biology and cancer. Oncogene, 29(3):313-324. DOI 10.1038/onc.2009.358.

Dick, J. M. (2008). Calculation of the relative metastabilities of proteins using the CHNOSZ software package. Geochemical Transactions, 9:10. DOI 10.1186/1467-4866-9-10.

Dick, J. M. (2014). Average oxidation state of carbon in proteins. Journal of the Royal Society Interface, 11:20131095. DOI 10.1098/rsif.2013.1095.

Dick, J. M., LaRowe, D. E., and Helgeson, H. C. (2006). Temperature, pressure, and electrochemical constraints on protein speciation: Group additivity calculation of the standard molal thermodynamic properties of ionized unfolded proteins. Biogeosciences, 3(3):311-336. DOI 10.5194/bg-3-311-2006. 
Duncan, S. H., Hold, G. L., Barcenilla, A., Stewart, C. S., and Flint, H. J. (2002). Roseburia intestinalis sp. nov., a novel saccharolytic, butyrate-producing bacterium from human faeces. International Journal of Systematic and Evolutionary Microbiology, 52(5):1615-1620. DOI 10.1099/00207713-52-5-1615.

Enver, T., Pera, M., Peterson, C., and Andrews, P. W. (2009). Stem cell states, fates, and the rules of attraction. Cell Stem Cell, 4(5):387-397. DOI 10.1016/j.stem.2009.04.011.

Fekete, J., Sajgó, C., Kramarics, A., Eke, Z., Kovács, K., and Kárpáti, Z. (2012). Aquathermolysis of humic and fulvic acids: Simulation of organic matter maturation in hot thermal waters. Organic Geochemistry, 53:109-118. DOI 10.1016/j.orggeochem.2012.07.005.

Feng, Q., Liang, S., Jia, H., Stadlmayr, A., Tang, L., Lan, Z., Zhang, D., Xia, H., Xu, X., Jie, Z., Su, L., Li, X., Li, X., Li, J., Xiao, L., Huber-Schönauer, U., Niederseer, D., Xu, X., Al-Aama, J. Y., Yang, H., Wang, J., Kristiansen, K., Arumugam, M., Tilg, H., Datz, C., and Wang, J. (2015). Gut microbiome development along the colorectal adenoma-carcinoma sequence. Nature Communications, 6:6528. DOI $10.1038 /$ ncomms7528.

Garrels, R. M. and Christ, C. L. (1965). Solutions, Minerals, and Equilibria. Harper \& Row, New York. URL http://www.worldcat.org/oclc/517586.

Gibbs, J. W. (1875). On the equilibrium of heterogeneous substances (first part). Transactions of the Connecticut Academy of Arts and Sciences, 3:108-248. URL http://archive.org/details/Onequilibriumhe00Gibb.

Grzegorczyk, T. M., Meaney, P. M., Kaufman, P. A., di Florio-Alexander, R. M., and Paulsen, K. D. (2012). Fast 3-D tomographic microwave imaging for breast cancer detection. IEEE Transactions on Medical Imaging, 31(8):1584-1592. DOI 10.1109/TMI.2012.2197218.

Gupta, V., Ganegoda, H., Engelhard, M. H., Terry, J., and Linford, M. R. (2014). Assigning oxidation states to organic compounds via predictions from X-ray photoelectron spectroscopy: A discussion of approaches and recommended improvements. Journal of Chemical Education, 91(2):232-238. DOI 10.1021/ed400401c.

Guzy, R. D. and Schumacker, P. T. (2006). Oxygen sensing by mitochondria at complex III: The paradox of increased reactive oxygen species during hypoxia. Experimental Physiology, 91(5):807-819. DOI 10.1113/expphysiol.2006.033506.

Halkides, C. J. (2000). Assigning and using oxidation numbers in biochemistry lecture courses. Journal of Chemical Education, 77(11):1428-1432. DOI 10.1021/ed077p1428.

Hansen, L. D., Hopkin, M. S., Rank, D. R., Anekonda, T. S., Breidenbach, R. W., and Criddle, R. S. (1994). The relation between plant growth and respiration: A thermodynamic model. Planta, 194(1):77-85. DOI 10.1007/BF00201037. 
Häussinger, D. (1996). The role of cellular hydration in the regulation of cell function. Biochemical Journal, 313:697-710. DOI 10.1042/bj3130697.

Helgeson, H. C. (1970). Description and interpretation of phase relations in geochemical processes involving aqueous solutions. American Journal of Science, 268(5):415-438. DOI 10.2475/ajs.268.5.415.

Helgeson, H. C., Kirkham, D. H., and Flowers, G. C. (1981). Theoretical prediction of the thermodynamic behavior of aqueous electrolytes at high pressures and temperatures: IV. Calculation of activity coefficients, osmotic coefficients, and apparent molal and standard and relative partial molal properties to $600^{\circ} \mathrm{C}$ and $5 \mathrm{~Kb}$. American Journal of Science, 281(10):1249-1516. DOI 10.2475/ajs.281.10.1249.

Helgeson, H. C., Richard, L., McKenzie, W. F., Norton, D. L., and Schmitt, A. (2009). A chemical and thermodynamic model of oil generation in hydrocarbon source rocks. Geochimica et Cosmochimica Acta, 73(3):594-695. DOI 10.1016/j.gca.2008.03.004.

Hendrickson, J. B., Cram, D. J., and Hammond, G. S. (1970). Organic Chemistry. McGraw-Hill, New York, 3rd edition. URL http://www.worldcat.org/oclc/78308.

Hiller, K. and Metallo, C. M. (2013). Profiling metabolic networks to study cancer metabolism. Current Opinion in Biotechnology, 24(1):60-68. DOI 10.1016/j.copbio.2012.11.001.

Höckel, M. and Vaupel, P. (2001). Tumor hypoxia: Definitions and current clinical, biologic, and molecular aspects. Journal of the National Cancer Institute, 93(4):266-276. DOI 10.1093/jnci/93.4.266.

Hutter, D. E., Till, B. G., and Greene, J. J. (1997). Redox state changes in density-dependent regulation of proliferation. Experimental Cell Research, 232(2):435-438. DOI 10.1006/excr.1997.3527.

Ihaka, R., Murrell, P., Hornik, K., Fisher, J. C., and Zeileis, A. (2015). colorspace: Color Space Manipulation. R package version 1.2-6.

Jankova, L., Chan, C., Fung, C. L. S., Song, X., Kwun, S. Y., Cowley, M. J., Kaplan, W., Dent, O. F., Bokey, E. L., Chapuis, P. H., Baker, M. S., Robertson, G. R., Clarke, S. J., and Molloy, M. P. (2011). Proteomic comparison of colorectal tumours and non-neoplastic mucosa from paired patient samples using iTRAQ mass spectrometry. Molecular Biosystems, 7:2997-3005. DOI 10.1039/C1MB05236E.

Jimenez, C. R., Knol, J. C., Meijer, G. A., and Fijneman, R. J. A. (2010). Proteomics of colorectal cancer: Overview of discovery studies and identification of commonly identified cancer-associated proteins and candidate CRC serum markers. Journal of Proteomics, 73(10):1873-1895. DOI 10.1016/j.jprot.2010.06.004.

Johnson, J. W., Oelkers, E. H., and Helgeson, H. C. (1992). SUPCRT92: A software package for calculating the standard molal thermodynamic properties of minerals, gases, aqueous species, and reactions from 1 to 5000 bar and 0 to $1000^{\circ} \mathrm{C}$. Computers \& Geosciences, 18(7):899-947. DOI 10.1016/0098-3004(92)90029-Q. 
Kang, U.-B., Yeom, J., Kim, H.-J., Kim, H., and Lee, C. (2012). Expression profiling of more than 3500 proteins of MSS-type colorectal cancer by stable isotope labeling and mass spectrometry. Journal of Proteomics, 75(10):3050-3062. DOI 10.1016/j.jprot.2011.11.021.

Kelley, K. K. (1960). Contributions to the Data in Theoretical Metallurgy XIII: High Temperature Heat Content, Heat Capacities and Entropy Data for the Elements and Inorganic Compounds. Bulletin 584. U. S. Bureau of Mines. URL http://www.worldcat.org/oclc/693388901.

Kim, H.-J., Kang, U.-B., Lee, H., Jung, J.-H., Lee, S.-T., Yu, M.-H., Kim, H., and Lee, C. (2012). Profiling of differentially expressed proteins in stage IV colorectal cancers with good and poor outcomes. Journal of Proteomics, 75(10):2983-2997. DOI 10.1016/j.jprot.2011.12.002.

Kinzler, K. W. and Vogelstein, B. (1996). Lessons from hereditary colorectal cancer. Cell, 87(2):159-170. DOI 10.1016/S0092-8674(00)81333-1.

Knezic, D., Zaccaro, J., and Myerson, A. S. (2004). Thermodynamic properties of supersaturated protein solutions. Crystal Growth \& Design, 4(1):199-208. DOI $10.1021 / \operatorname{cg} 034072$ o.

Knol, J. C., de Wit, M., Albrethsen, J., Piersma, S. R., Pham, T. V., Mongera, S., Carvalho, B., Fijneman, R. J. A., Meijer, G. A., and Jiménez, C. R. (2014). Proteomics of differential extraction fractions enriched for chromatin-binding proteins from colon adenoma and carcinoma tissues. Biochimica et Biophysica Acta (BBA) - Proteins and Proteomics, 1844(5):1034-1043. DOI 10.1016/j.bbapap.2013.12.006.

Kondepudi, D. K. and Prigogine, I. (1998). Modern Thermodynamics: From Heat Engines to Dissipative Structures. John Wiley \& Sons, New York. URL http://www.worldcat.org/oclc/38055900.

Kostic, A. D., Gevers, D., Pedamallu, C. S., Michaud, M., Duke, F., Earl, A. M., Ojesina, A. I., Jung, J., Bass, A. J., Tabernero, J., Baselga, J., Liu, C., Shivdasani, R. A., Ogino, S., Birren, B. W., Huttenhower, C., Garrett, W. S., and Meyerson, M. (2012). Genomic analysis identifies association of Fusobacterium with colorectal carcinoma. Genome Research, 22(2):292-298. DOI 10.1101/gr.126573.111.

Kroll, J. H., Donahue, N. M., Jimenez, J. L., Kessler, S. H., Canagaratna, M. R., Wilson, K. R., Altieri, K. E., Mazzoleni, L. R., Wozniak, A. S., Bluhm, H., Mysak, E. R., Smith, J. D., Kolb, C. E., and Worsnop, D. R. (2011). Carbon oxidation state as a metric for describing the chemistry of atmospheric organic aerosol. Nature Chemistry, 3(2):133-139. DOI 10.1038/nchem.948.

LaRowe, D. E. and Dick, J. M. (2012). Calculation of the standard molal thermodynamic properties of crystalline peptides. Geochimica et Cosmochimica Acta, 80:70-91. DOI 10.1016/j.gca.2011.11.041. 
Lazaridis, T. and Karplus, M. (2003). Thermodynamics of protein folding: A microscopic view. Biophysical Chemistry, 100(1-3):367-395. DOI 10.1016/S0301-4622(02)00293-4.

Levy, Y. and Onuchic, J. N. (2006). Water mediation in protein folding and molecular recognition. Annual Review of Biophysics and Biomolecular Structure, 35:389-415. DOI 10.1146/annurev.biophys.35.040405.102134.

Li, M., Peng, F., Li, G., Fu, Y., Huang, Y., Chen, Z., and Chen, Y. (2016). Proteomic analysis of stromal proteins in different stages of colorectal cancer establishes Tenascin-C as a stromal biomarker for colorectal cancer metastasis. Oncotarget, 5(0). DOI 10.18632/oncotarget.9362.

Loock, H.-P. (2011). Expanded definition of the oxidation state. Journal of Chemical Education, 88(3):282-283. DOI 10.1021/ed1005213.

Louis, P. and Flint, H. J. (2007). Development of a semiquantitative degenerate real-time PCR-based assay for estimation of numbers of butyryl-coenzyme A (CoA) CoA transferase genes in complex bacterial samples. Applied and Environmental Microbiology, 73(6):2009-2012. DOI 10.1128/AEM.02561-06.

Martinez-Outschoorn, U. E., Lisanti, M. P., and Sotgia, F. (2014). Catabolic cancer-associated fibroblasts transfer energy and biomass to anabolic cancer cells, fueling tumor growth. Seminars in Cancer Biology, 25:47-60. DOI 10.1016/j.semcancer.2014.01.005.

Martínez-Aguilar, J., Chik, J., Nicholson, J., Semaan, C., McKay, M. J., and Molloy, M. P. (2013). Quantitative mass spectrometry for colorectal cancer proteomics. Proteomics: Clinical Applications, 7(1-2):42-54. DOI 10.1002/prca.201200080.

Masiello, C. A., Gallagher, M. E., Randerson, J. T., Deco, R. M., and Chadwick, O. A. (2008). Evaluating two experimental approaches for measuring ecosystem carbon oxidation state and oxidative ratio. Journal of Geophysical Research, 113(G3):G03010. DOI 10.1029/2007JG000534.

May, P. M. and Murray, K. (2001). Database of chemical reactions designed to achieve thermodynamic consistency automatically. Journal of Chemical \& Engineering Data, 46(5):1035-1040. DOI 10.1021/je000246j.

McIntyre, G. I. (2006). Cell hydration as the primary factor in carcinogenesis: A unifying concept. Medical Hypotheses, 66(3):518-526. DOI 10.1016/j.mehy.2005.09.022.

Mikula, M., Rubel, T., Karczmarski, J., Goryca, K., Dadlez, M., and Ostrowski, J. (2011). Integrating proteomic and transcriptomic high-throughput surveys for search of new biomarkers of colon tumors. Functional and Integrative Genomics, 11(2):215-224. DOI 10.1007/s10142-010-0200-5.

Morel, F. M. M. and Hering, J. G. (1993). Principles and Applications of Aquatic Chemistry. John Wiley \& Sons. URL http://www.worldcat.org/oclc/26013680. 
Moura, A., Savageau, M. A., and Alves, R. (2013). Relative amino acid composition signatures of organisms and environments. PLoS ONE, 8(10):e77319. DOI 10.1371/journal.pone.0077319.

Mu, Y., Chen, Y., Zhang, G., Zhan, X., Li, Y., Liu, T., Li, G., Li, M., Xiao, Z., Gong, X., and Chen, Z. (2013). Identification of stromal differentially expressed proteins in the colon carcinoma by quantitative proteomics. Electrophoresis, 34(11):1679-1692. DOI 10.1002/elps.201200596.

Murphy, M. P. (2009). How mitochondria produce reactive oxygen species. Biochemical Journal, 417:1-13. DOI 10.1042/bj20081386.

Nagai, F., Morotomi, M., Sakon, H., and Tanaka, R. (2009). Parasutterella excrementihominis gen. nov., sp. nov., a member of the family Alcaligenaceae isolated from human faeces. International Journal of Systematic and Evolutionary Microbiology, 59(7):1793-1797. DOI 10.1099/ijs.0.002519-0.

Pace, N. R. (1991). Origin of life: Facing up to the physical setting. Cell, 65(4):531-533. DOI 10.1016/0092-8674(91)90082-A.

Peng, F., Huang, Y., Li, M.-Y., Li, G.-Q., Huang, H.-C., Guan, R., Chen, Z.-C., Liang, S.-P., and Chen, Y.-H. (2016). Dissecting characteristics and dynamics of differentially expressed proteins during multistage carcinogenesis of human colorectal cancer. World Journal of Gastroenterology, 22(18):4515-4528. DOI 10.3748/wjg.v22.i18.4515.

R Core Team (2016). R: A Language and Environment for Statistical Computing. $\mathrm{R}$ Foundation for Statistical Computing, Vienna, Austria.

Ravi Kanth, M. V. S. R., Pushpavanam, S., Narasimhan, S., and Narasimha, M. B. (2014). A robust and efficient algorithm for computing reactive equilibria in single and multiphase systems. Industrial \& Engineering Chemistry Research, 53(39):15278-15286. DOI 10.1021/ie502639a.

Riedel, T., Biester, H., and Dittmar, T. (2012). Molecular fractionation of dissolved organic matter with metal salts. Environmental Science \& Technology, 46(8):4419-4426. DOI 10.1021/es203901u.

Rietman, E. A., Platig, J., Tuszynski, J. A., and Lakka Klement, G. (2016). Thermodynamic measures of cancer: Gibbs free energy and entropy of protein-protein interactions. Journal of Biological Physics, pages 1-12. DOI 10.1007/s10867-016-9410-y.

Rogmann, J. J. (2013). orddom: Ordinal Dominance Statistics. R package version 3.1.

Russell, M. J. and Hall, A. J. (1997). The emergence of life from iron monosulphide bubbles at a submarine hydrothermal redox and $\mathrm{pH}$ front. Journal of the Geological Society, 154:377-402. DOI 10.1144/gsjgs.154.3.0377. 
Schafer, F. Q. and Buettner, G. R. (2001). Redox environment of the cell as viewed through the redox state of the glutathione disulfide/glutathione couple. Free Radical Biology and Medicine, 30(11):1191-1212. DOI 10.1016/S0891-5849(01)00480-4.

Schedin, P. and Elias, A. (2004). Multistep tumorigenesis and the microenvironment. Breast Cancer Research, 6(2):93-101. DOI 10.1186/bcr772.

Semenza, G. L. (2008). Tumor metabolism: Cancer cells give and take lactate. Journal of Clinical Investigation, 118(12):3835-3837. DOI 10.1172/JCI37373.

Sethi, M. K., Thaysen-Andersen, M., Kim, H., Park, C. K., Baker, M. S., Packer, N. H., Paik, Y.-K., Hancock, W. S., and Fanayan, S. (2015). Quantitative proteomic analysis of paired colorectal cancer and non-tumorigenic tissues reveals signature proteins and perturbed pathways involved in CRC progression and metastasis. Journal of Proteomics, 126:54-67. DOI 10.1016/j.jprot.2015.05.037.

Shock, E. and Canovas, P. (2010). The potential for abiotic organic synthesis and biosynthesis at seafloor hydrothermal systems. Geofluids, 10(1-2):161-192. DOI 10.1111/j.1468-8123.2010.00277.x.

Sokol, H., Pigneur, B., Watterlot, L., Lakhdari, O., Bermúdez-Humarán, L. G., Gratadoux, J.-J., Blugeon, S., Bridonneau, C., Furet, J.-P., Corthier, G., Grangette, C., Vasquez, N., Pochart, P., Trugnan, G., Thomas, G., Blottière, H. M., Doré, J., Marteau, P., Seksik, P., and Langella, P. (2008). Faecalibacterium prausnitzii is an anti-inflammatory commensal bacterium identified by gut microbiota analysis of Crohn disease patients. Proceedings of the National Academy of Sciences of the United States of America, 105(43):16731-16736. DOI 10.1073/pnas.0804812105.

Stevenson, A., Cray, J. A., Williams, J. P., Santos, R., Sahay, R., Neuenkirchen, N., McClure, C. D., Grant, I. R., Houghton, J. D., Quinn, J. P., Timson, D. J., Patil, S. V., Singhal, R. S., Anton, J., Dijksterhuis, J., Hocking, A. D., Lievens, B., Rangel, D. E. N., Voytek, M. A., Gunde-Cimerman, N., Oren, A., Timmis, K. N., McGenity, T. J., and Hallsworth, J. E. (2015). Is there a common water-activity limit for the three domains of life? ISME Journal, 9(6):1333-1351. DOI 10.1038/ismej.2014.219.

Tanger, IV, J. C. and Helgeson, H. C. (1988). Calculation of the thermodynamic and transport properties of aqueous species at high pressures and temperatures: Revised equations of state for the standard partial molal properties of ions and electrolytes. American Journal of Science, 288(1):19-98. DOI 10.2475/ajs.288.1.19.

Tekaia, F. and Yeramian, E. (2006). Evolution of proteomes: Fundamental signatures and global trends in amino acid compositions. BMC Genomics, 7:307. DOI 10.1186/1471-2164-7-307.

The UniProt Consortium (2015). UniProt: A hub for protein information. Nucleic Acids Research, 43(D1):D204-D212. DOI 10.1093/nar/gku989.

Toole, B. P. (2002). Hyaluronan promotes the malignant phenotype. Glycobiology, 12(3):37R-42R. DOI 10.1093/glycob/12.3.37R. 
Uzozie, A., Nanni, P., Staiano, T., Grossmann, J., Barkow-Oesterreicher, S., Shay, J. W., Tiwari, A., Buffoli, F., Laczko, E., and Marra, G. (2014). Sorbitol dehydrogenase overexpression and other aspects of dysregulated protein expression in human precancerous colorectal neoplasms: A quantitative proteomics study. Molecular \& Cellular Proteomics, 13(5):1198-1218. DOI 10.1074/mcp.M113.035105.

VanBriesen, J. M. and Rittmann, B. E. (1999). Modeling speciation effects on biodegradation in mixed metal/chelate systems. Biodegradation, 10(5):315-330. DOI 10.1023/A:1008375722721.

Wagman, D. D., Evans, W. H., Parker, V. B., Schumm, R. H., Halow, I., Bailey, S. M., Churney, K. L., and Nuttall, R. L. (1982). The NBS tables of chemical thermodynamic properties. Selected values for inorganic and $C_{1}$ and $C_{2}$ organic substances in SI units. Journal of Physical and Chemical Reference Data, 11(Suppl. 2):1-392.

Wang, T., Cai, G., Qiu, Y., Fei, N., Zhang, M., Pang, X., Jia, W., Cai, S., and Zhao, L. (2012). Structural segregation of gut microbiota between colorectal cancer patients and healthy volunteers. ISME Journal, 6(2):320-329. DOI 10.1038/ismej.2011.109.

Watanabe, M., Takemasa, I., Kawaguchi, N., Miyake, M., Nishimura, N., Matsubara, T., Matsuo, E.-i., Sekimoto, M., Nagai, K., Matsuura, N., Monden, M., and Nishimura, O. (2008). An application of the 2-nitrobenzenesulfenyl method to proteomic profiling of human colorectal carcinoma: A novel approach for biomarker discovery. Proteomics: Clinical Applications, 2(6):925-935. DOI 10.1002/prca.200780111.

Wedberg, R., Abildskov, J., and Peters, G. H. (2012). Protein dynamics in organic media at varying water activity studied by molecular dynamics simulation. Journal of Physical Chemistry B, 116(8):2575-2585. DOI 10.1021/jp211054u.

Weir, T. L., Manter, D. K., Sheflin, A. M., Barnett, B. A., Heuberger, A. L., and Ryan, E. P. (2013). Stool microbiome and metabolome differences between colorectal cancer patients and healthy adults. PLoS ONE, 8(8):e70803. DOI 10.1371/journal.pone.0070803.

Wiśniewski, J. R., Duś-Szachniewicz, K., Ostasiewicz, P., Ziółkowski, P., Rakus, D., and Mann, M. (2015). Absolute proteome analysis of colorectal mucosa, adenoma, and cancer reveals drastic changes in fatty acid metabolism and plasma membrane transporters. Journal of Proteome Research, 14(9):4005-4018. DOI 10.1021/acs.jproteome.5b00523.

Wiśniewski, J. R., Ostasiewicz, P., Duś, K., Zielińska, D. F., Gnad, F., and Mann, M. (2012). Extensive quantitative remodeling of the proteome between normal colon tissue and adenocarcinoma. Molecular Systems Biology, 8(1):611. DOI 10.1038/msb.2012.44.

Xie, L.-Q., Zhao, C., Cai, S.-J., Xu, Y., Huang, L.-Y., Bian, J.-S., Shen, C.-P., Lu, H.-J., and Yang, P.-Y. (2010). Novel proteomic strategy reveal combined $\alpha 1$ antitrypsin and 
cathepsin D as biomarkers for colorectal cancer early screening. Journal of Proteome Research, 9(9):4701-4709. DOI 10.1021/pr100406z.

Yang, H.-Y., Chay, K.-O., Kwon, J., Kwon, S.-O., Park, Y.-K., and Lee, T.-H. (2013). Comparative proteomic analysis of cysteine oxidation in colorectal cancer patients. Molecules and Cells, 35(6):533-542. DOI 10.1007/s10059-013-0058-1.

Yao, L., Lao, W., Zhang, Y., Tang, X., Hu, X., He, C., Hu, X., and Xu, L. X. (2012). Identification of EFEMP2 as a serum biomarker for the early detection of colorectal cancer with lectin affinity capture assisted secretome analysis of cultured fresh tissues. Journal of Proteome Research, 11(6):3281-3294. DOI 10.1021/pr300020p.

Yeh, C.-C., Lai, C.-Y., Hsieh, L.-L., Tang, R., Wu, F.-Y., and Sung, F.-C. (2010). Protein carbonyl levels, glutathione S-transferase polymorphisms and risk of colorectal cancer. Carcinogenesis, 31(2):228-233. DOI 10.1093/carcin/bgp286.

Zeileis, A., Hornik, K., and Murrell, P. (2009). Escaping RGBland: Selecting colors for statistical graphics. Computational Statistics and Data Analysis, 53(9):3259-3270. DOI 10.1016/j.csda.2008.11.033.

Zeldovich, K. B., Berezovsky, I. N., and Shakhnovich, E. I. (2007). Protein and DNA sequence determinants of thermophilic adaptation. PLoS Computational Biology, 3(1):62-72. DOI 10.1371/journal.pcbi.0030005.

Zeller, G., Tap, J., Voigt, A. Y., Sunagawa, S., Kultima, J. R., Costea, P. I., Amiot, A., Böhm, J., Brunetti, F., Habermann, N., Hercog, R., Koch, M., Luciani, A., Mende, D. R., Schneider, M. A., Schrotz-King, P., Tournigand, C., Tran Van Nhieu, J., Yamada, T., Zimmermann, J., Benes, V., Kloor, M., Ulrich, C. M., von Knebel Doeberitz, M., Sobhani, I., and Bork, P. (2014). Potential of fecal microbiota for early-stage detection of colorectal cancer. Molecular Systems Biology, 10(11):766. DOI 10.15252/msb.20145645.

Zhang, Y., Ye, Y., Shen, D., Jiang, K., Zhang, H., Sun, W., Zhang, J., Xu, F., Cui, Z., and Wang, S. (2010). Identification of transgelin-2 as a biomarker of colorectal cancer by laser capture microdissection and quantitative proteome analysis. Cancer Science, 101(2):523-529. DOI 10.1111/j.1349-7006.2009.01424.x. 